\title{
3,4-Ethylenedioxythiophene (EDOT) End-Group Functionalized Poly- $\varepsilon$-caprolactone (PCL): Self-Assembly in Organic Solvents and Its Coincidentally Observed Peculiar Behavior in Thin Film and Protonated Media
}

\author{
Anca-Dana Bendrea ${ }^{1}$, Luminita Cianga ${ }^{1, *}$, Gabriela-Liliana Ailiesei ${ }^{2} \mathbb{D}$, Elena-Laura Ursu ${ }^{1}$, Demet Göen Colak ${ }^{3}$ \\ and Ioan Cianga ${ }^{1, *}$
}

1 Centre of Advanced Research in Bionanoconjugates and Biopolymers, "Petru Poni" Institute of Macromolecular Chemistry, 41A, Grigore-Ghica Voda Alley, 700487 Iasi, Romania; anca.bendrea@icmpp.ro (A.-D.B.); ursu.laura@icmpp.ro (E.-L.U.)

2 NMR Spectroscopy Department, "Petru Poni" Institute of Macromolecular Chemistry, 41A, Grigore-Ghica Voda Alley, 700487 Iasi, Romania; gdarvaru@icmpp.ro

3 Department of Chemistry, Faculty of Science and Letters, Istanbul Technical University, Maslak, Istanbul 34469, Turkey; goende@itu.edu.tr

* Correspondence: 1cianga@icmpp.ro (L.C.); ioanc@icmpp.ro (I.C.)

check for updates

Citation: Bendrea, A.-D.; Cianga, L.; Ailiesei, G.-L.; Ursu, E.-L.; Göen Colak, D.; Cianga, I.

3,4-Ethylenedioxythiophene (EDOT) End-Group Functionalized

Poly- $\varepsilon$-caprolactone (PCL):

Self-Assembly in Organic Solvents and Its Coincidentally Observed Peculiar Behavior in Thin Film and Protonated Media. Polymers 2021, 13, 2720. https://doi.org/10.3390/ polym 13162720

Academic Editor: Esther Rebollar

Received: 24 June 2021

Accepted: 12 August 2021

Published: 14 August 2021

Publisher's Note: MDPI stays neutral with regard to jurisdictional claims in published maps and institutional affiliations.

Copyright: (c) 2021 by the authors. Licensee MDPI, Basel, Switzerland. This article is an open access article distributed under the terms and conditions of the Creative Commons Attribution (CC BY) license (https:/ / creativecommons.org/licenses/by/ $4.0 /)$.

\begin{abstract}
End-group functionalization of homopolymers is a valuable way to produce high-fidelity nanostructured and functional soft materials when the structures obtained have the capacity for self-assembly (SA) encoded in their structural details. Herein, an end-functionalized PCL with a $\pi$-conjugated EDOT moiety, (EDOT-PCL), designed exclusively from hydrophobic domains, as a functional "hydrophobic amphiphile", was synthesized in the bulk ROP of $\varepsilon$-caprolactone. The experimental results obtained by spectroscopic methods, including NMR, UV-vis, and fluorescence, using DLS and by AFM, confirm that in solvents with extremely different polarities (chloroform and acetonitrile), EDOT-PCL presents an interaction- and structure-based bias, which is strong and selective enough to exert control over supramolecular packing, both in dispersions and in the film state. This leads to the diversity of SA structures, including spheroidal, straight, and helical rods, as well as orthorhombic single crystals, with solvent-dependent shapes and sizes, confirming that EDOTPCL behaves as a "block-molecule". According to the results from AFM imaging, an unexpected transformation of micelle-type nanostructures into single 2D lamellar crystals, through breakout crystallization, took place by simple acetonitrile evaporation during the formation of the film on the mica support at room temperature. Moreover, EDOT-PCL's propensity for spontaneous oxidantfree oligomerization in acidic media was proposed as a presumptive answer for the unexpected appearance of blue color during its dissolution in $\mathrm{CDCl}_{3}$ at a high concentration. FT-IR, UV-vis, and fluorescence techniques were used to support this claim. Besides being intriguing and unforeseen, the experimental findings concerning EDOT-PCL have raised new and interesting questions that deserve to be addressed in future research.
\end{abstract}

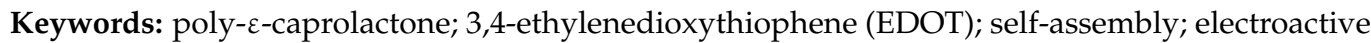
macromonomers; amphiphiles; polymer single crystals; micelles; ${ }^{1} \mathrm{H}$ - and $2 \mathrm{D}$-correlated ${ }^{1} \mathrm{H}-{ }^{1} \mathrm{H}-\mathrm{NMR}$ spectroscopy analysis; atom force microscopy (AFM)

\section{Introduction}

Today, a plausible way to find new functions of conventional polymers, in order to better fit a given application, is through high-precision polymers with complex architectures [1]. As different properties have been demonstrated through a comparison with the classical, linear arrangement of the chain [2], the goal of producing polymers with complex architectures can be achieved by applying the concept "from functionality to 
function". In this regard, polymeric materials with specific chain-end functionality have become accessible, especially through "living" controlled polymerizations $[3,4]$, which have led to the production of valuable materials with new and improved properties [5-7] and to reactive intermediates of great interest for the construction of polymers with defined molecular architectures $[4,8,9]$. In bulk, in solution, or in film, placed at the chain-end of the homopolymers or copolymers, and even in blends of them, the end-groups impact their properties at both the molecular and supramolecular level. It is interesting that, in spite of the small content of terminal groups as compared to the macromolecular backbone, this effect is more pronounced if they are placed in confined spaces. One consequence of the confinement effect caused by the end-group is that the block copolymers morphology is radically modified, resulting in unparalleled property changes [8]. Additionally, the existing polymer properties, such as enzymatic degradation [6], of the solution-protein interaction [10] or the drug loading capacity [5] can be manipulated through the functional end-groups, or other new properties can be added such as fluorescence properties $[7,11]$.

Basically, there are two approaches to the synthesis of end-functional polymers: (i) $\alpha$ functionalization or the so-called "initiation method", which makes use of a functionalized initiator in a controlled type polymerization and (ii) $\omega$-functionalization, which can be accomplished post-polymerization, by modifying the existing chain ends with the desired functionality; a combination of these variants can be applied.

Various types of functional end-groups have been introduced into a plethora, and progressively, a diverse range of polymers, such as (poly(ethyleneglycol) (PEG) [12], poly(lactide) PLA [13], poly(N-alkyl-oxazoline)s (POXA) [14], poly(N-isopropylacrylamide) (PNIPAM), poly(methyl methacrylate) (PMMA), poly(ethylene glycol methyl ether methacrylate) POEGMA [15], polystyrene (PSt) [16,17], polyethylene, (PE) [18], and polypeptides [19], using various "living" polymerization methods, including atom transfer radical polymerization (ATRP) [16], nitroxide-mediated polymerization (NMP) [17], reversible addition-fragmentation chain transfer (RAFT) [15], and ring-opening polymerization (ROP [13,19], CROP [14], and ROMP [18]). These are often combined with post-polymerization chemical modifications $[12,16]$. Besides these polymers, PCL, which belongs to the first generation of synthetic aliphatic polyesters [20], is among the earliest studied biomaterials of synthetic nature. The biodegradability of PCL has led to its extensive exploration for various bioapplications [21].

Being widely commercially available, PCL has a high capacity to be miscibly blended, and this has resulted in interesting compatibilization studies [22-24]. Whether in blends or copolymers of various architectures [25-27], PCL is easily shaped and manufactured in the form of hydrogels [22,23], nanoparticles [24], nanofibers [27,28], and, more importantly, due to its crystallizable nature, into a well-defined and geometrically shaped 2D lamellar single-crystal structure that has various and interesting applications $[25,29]$.

Due to the renewed interest in $\varepsilon$-caprolactone-derived components for the construction of systems with advanced functions, various functional groups have been added by the end-group functionalization. Thus, innovative uses of $\varepsilon$-caprolactone-based segments in sophisticated polymer architectures or micellar systems have also been noted [21]. Thus, the end-group functionalization of PCL means that it can be applied in, for example, more efficient drug delivery systems [5,11] and in aggregation-induced emission (AIE) materials [7], as catalytically active recyclable materials, or as magnetically responsive, luminescent materials [29]. Moreover, functional groups have often been added to PCL to transform it into a reactive intermediate in order to subsequently use them in coupling reactions. These reactions led to various macromolecular structures [26,30], macroinitiators [31,32], and, very importantly, well-defined macromonomers [33-35]. Macromonomers are, in fact, oligomer or polymer chains that are functionalized with polymerizable end-groups. The homopolymerization of macromonomers, which results in "polymacromonomers", has evolved as a strong strategy to obtain "(macro)molecular (bottle)brushes" or "cylindrical polymer brushes" [36,37]. Today, this class of complex polymer architectures works as 
a versatile toolbox of anisotropic building blocks for next-generation nanomaterials [37]. These are suitable for applications in key fields, including nanomedicine [38].

Electroactive macromonomers, so named due to their ability to oxidatively polymerize using electrochemical techniques [12,17], are also active in chemically oxidative polycondensation [13-16] or, alternatively, in other polymerization methods specifically designed to obtain conjugated polymers (CPs) [9,34]. These macromonomers are important building blocks, the use of which has enabled the enlargement of the CPs "hairy-rods" class [39] and has allowed for well-defined oligomeric/polymeric flexible side chains to be attached to the conjugated, rigid backbones, resulting in graft rod-coil type polymers with a self-assembling propensity and high flexibility in the tuning of properties. Several such PCL-derived electroactive macromonomers have already been reported [40-42].

In some cases [41,42], the introduction of PCL side chains to the conjugated backbones has contributed to increased biocompatibility and efficiency when working in biorelevant aqueous electrolytes of the obtained materials. In the case of a heterografted polythiophene, such introduction contributed to the development of a material whose weight was composed mainly of PCL and PEG commodity polymers [43], which also showed that its amphiphilic nature allows for the manipulation of the self-assembled morphology by solvent selectivity and concentration of solutions.

Therefore, it is clear that in being endowed with the unique combination of polymer and monomer-like properties, the macromonomers' structural details are reflected in the characteristics of the materials that are constructed based on them. Thus, as electroactive macromonomers' behavior in instances with significance for further applications, it is a rational, necessary step; in this paper, we focused on properties in solution and on the morphology in thin films of such a compound.

Based on our previous experience with electroactive macromonomers synthesis [12,14,16,17], we recently engineered and reported [42] EDOT-PCL (Scheme 1) as a new structure, based on EDOT and oligo- $\varepsilon$-caprolactone (OCL). Our option was made with the knowledge that OCL, which has a molecular weight of less than $3000 \mathrm{Da}$, undergoes phagocytosis by the phagosomes of macrophages and giant cells, followed by intracellular degradation by esterases. This type of OCL in various combinations can produce useful biomaterials that solve the slow degradation problems of PCL [44].

The reported macromonomer, EDOT-PCL, was shown to be the key element in the incorporation of $\mathrm{CP}$ PEDOT into a 3D polymeric flexible and electroactive bioplatform. It was also shown to have favorable properties that enhanced the tissue integration performance of implantable medical devices [42].

It is noteworthy that, very recently, a combination of PEDOT or oligomers of EDOT with PCLs, as blends [45] or as linear and hyper-branched copolymers [46] in the form of nanofibers or hydrogels, appropriate for skeletal muscle or neural tissue engineering, was also developed. This emphasizes the current interest in the combination of the two for bioapplications.

Scheme 1 shows the reaction path of EDOT-PCL synthesis and, in a schematic manner, the design criteria that were taken into account in tailoring it. OCL, in addition to being biocompatible, with a high ionic conductivity, ion solvation capacity, and a wide window of electrochemical stability [42], is a well-known hydrophobic, flexible, semicrystalline, polar, and biodegradable polymer [21]. In contrast, EDOT is a flat, aromatic, and rigid combination of two fused rings. Its electroactivity and polymerization capacity have recently been demonstrated [42].

Moreover, due to its aromatic character, this fragment is photosensitive and is capable of non-covalent intermolecular stacking through $\pi-\pi$ interactions. At the opposite end, EDOT-PCL exposes a hydroxyl group, which could not only be used for subsequent chemical modifications but could also form intermolecular hydrogen bonds.

Due to the aforementioned differences in the structural details of its components, we associated EDOT-PCL with the term "hydrophobic amphiphile" due to its design being similar to $\pi$-conjugated fullerene-C60-alkyl molecules introduced by Nakanishi 
et al. [47]. These authors extended the amphiphilic assembly concept in aqueous environments to molecules that are solely made up of hydrophobic domains. In organic solvents, self-assembled structures, similar to the structures of classical amphiphiles, were demonstrated [47].
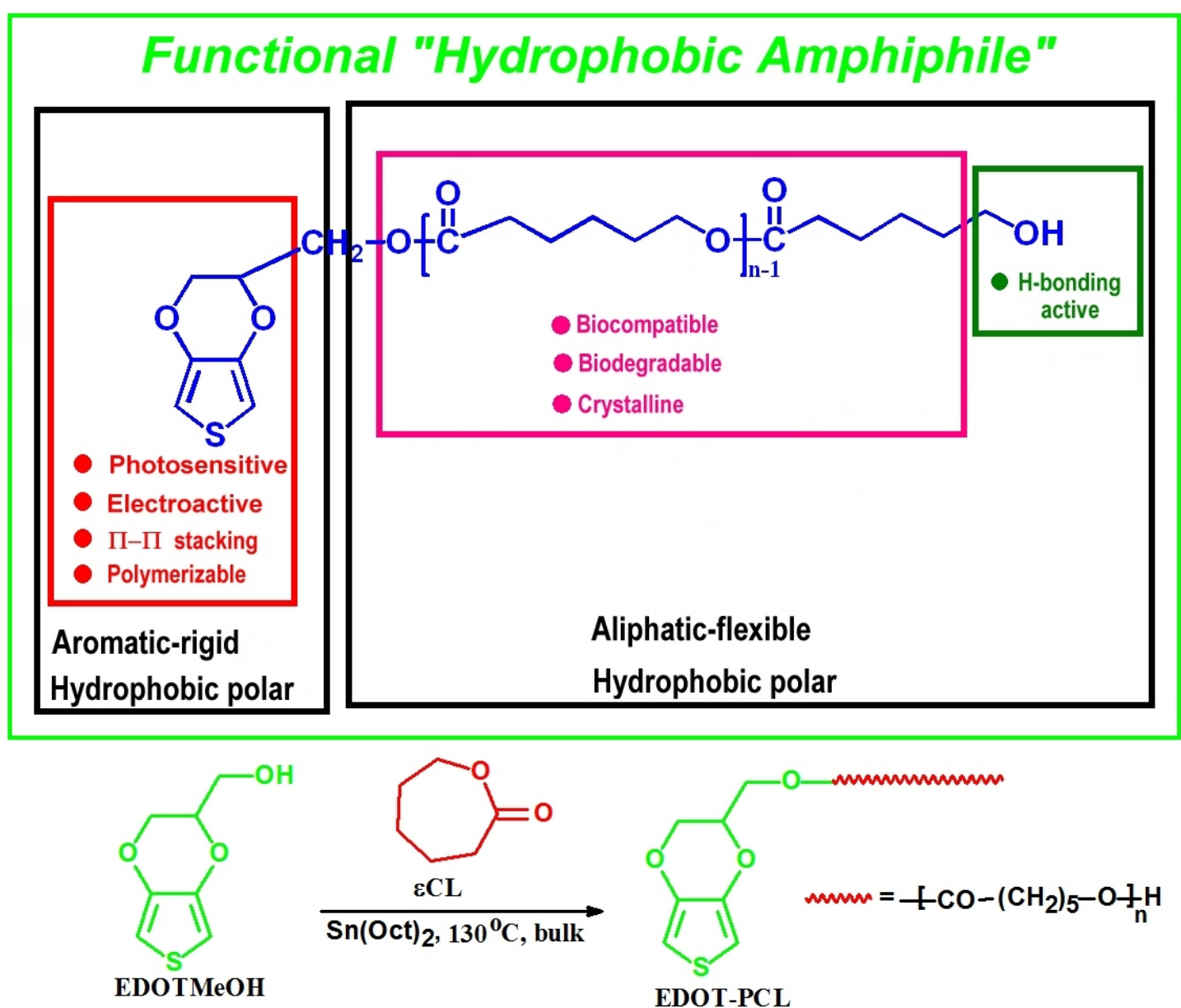

Scheme 1. The functional characteristics of the EDOT-PCL macromonomer and the pathway for its synthesis.

Moreover, an experimental exploration unexpectedly revealed that microphase separation behavior is sometimes witnessed in a single polymer during end-group functionalization $[48,49]$. In most cases, this occurs in polymers with flexible backbones and bulky terminal groups that are capable of strong planar interactions [8].

However, anisotropy in shape and stiffness has only recently been recognized as an important parameter in the fine-tuning of the self-assembled structures of the so-called "shape amphiphiles". In addition to the difference in interactions with solvents, which is inherent to some degree in any block system, the shape effect and the mismatch in rigidity are overwhelming factors that lead to the self-assembly of compounds that are constructed based on the characteristic criteria of the "shape amphiphiles" [50].

As can be seen in Scheme 1, the EDOT-PCL structure shows almost all the "ingredients" mentioned above for particular behaviors. Thus, in this study, we focused on showing the impact of the final EDOT group on OCL properties and investigating the EDOT-PCL capacity of self-assembly in solution and the subsequent morphological transitions that occurred during thin film formation. The solvents used, chloroform (Chl) and acetonitrile $(\mathrm{ACN})$, were deliberately chosen in order to show the significant influence caused by their difference in polarity and because they are commonly used as reaction media for chemical and electrochemical polymerization $[42,43,51]$. An explanation is also given for 
the transition from colorless to blue color that was observed during the preparation of a concentrated solution of EDOT-PCL in CDCl3.

\section{Materials and Methods}

\subsection{Materials}

Hydroxymethyl-3,4-ethylenedioxythiophene (EDOTMeOH; 95\% Sigma-Aldrich, Darmstadt, Germany), $\varepsilon$-caprolactone ( $\varepsilon$-CL Aldrich, Darmstadt, Germany), and stannous octanoate $\left(\mathrm{Sn}(\mathrm{Oct})_{2}\right)$ (Sigma, Darmstadt, Germany) were used as received. All the solvents were purified and dried using the usual methods.

\subsection{Synthesis of EDOT-PCL Macromonomer}

Under nitrogen, $21.75 \mathrm{mmol}$ of $\varepsilon$-CL, $1.45 \mathrm{mmol}$ of EDOTMeOH and $0.00725 \mathrm{mmol}$ of $\mathrm{Sn}$ (Oct), in a ratio of (I) /(M) / (cat) $=200 / 3000 / 1$ were added to a previously flamed and nitrogen-purged two-neck round-bottom flask that was equipped with a dropping funnel and a magnetic stirrer. The $\varepsilon$-CL polymerization was carried out in bulk at $130{ }^{\circ} \mathrm{C}$. After $24 \mathrm{~h}$ of reaction, the resulting mixture was diluted with an amount of $\mathrm{CHCl}_{3}$ and was poured into a 10-fold excess of cold methanol. The resulting EDOT-PCL macromonomer was collected after filtration and was dried at room temperature in a vacuum for 3 days [42].

\subsection{Measurements}

The NMR spectra were recorded on a Bruker Avance NEO $400 \mathrm{MHz}$ spectrometer (Bruker BioSpin $\mathrm{GmbH}$, Rheinstetten, Germany, ) operating at $400.1 \mathrm{MHz}$ for ${ }^{1} \mathrm{H}$ and $100.6 \mathrm{MHz}$ for ${ }^{13} \mathrm{C}$ nuclei, equipped with a $5 \mathrm{~mm}$ four-nuclei direct detection z-gradient probe using standard pulse sequences, as delivered by Bruker with TopSpin 4.0.8 spectrometer control and processing software. Chemical shifts are reported in $\delta$ units (ppm) and were referenced to the residual solvent signal $\left(\mathrm{CD}_{3} \mathrm{CN}\right.$ at $1.93 \mathrm{ppm}$ and $118.19 \mathrm{ppm}$ for ${ }^{1} \mathrm{H}-\mathrm{NMR}$ and ${ }^{13} \mathrm{C}$-NMR, respectively; $\mathrm{CDCl}_{3}$ at $7.26 \mathrm{ppm}$ for ${ }^{1} \mathrm{H}$-NMR). All the experiments were recorded at room temperature $\left(24{ }^{\circ} \mathrm{C}\right)$. The $2 \mathrm{D}^{1} \mathrm{H}-{ }^{1} \mathrm{H}$ NOESY spectrum was recorded using a phase-sensitive NOESY pulse sequence, with a number of scans of 64 , a spectral resolution of $2.37 \mathrm{~Hz}$, and a mixing time of $0.8 \mathrm{~s}$.

The FTIR spectra were recorded on a Bruker Vertex 70 FTIR spectrometer in the transmission mode using $\mathrm{KBr}$ pellets.

The molecular weight of the EDOT-PCL macromonomer was estimated from ${ }^{1} \mathrm{H}-$ NMR data, using a similar algorithm as previously reported [42], and the obtained value of $\mathrm{M}_{\mathrm{n}}{ }^{1} \mathrm{H}$-NMR $(1998 \mathrm{Da}$ ) indicated a degree of polymerization (PD) of 16. Thus, regardless of the solvent used for the NMR registration, it can be seen that the obtained result was in line with the previously reported result $(\mathrm{PD}=16.5)$ obtained for $\mathrm{CDCl}_{3}[42]$.

UV-vis absorption spectra were measured using a Specord 200 Analytik Jena spectrophotometer. Fluorescence measurements were carried out using a Perkin Elmer LS 55 apparatus. The measurements were performed in $\mathrm{CHCl}_{3}$ and acetonitrile with the concentrations of the solutions kept constant at $1 \mathrm{mg} / \mathrm{mL}\left(0.49 \times 10^{-6} \mathrm{M}\right)$. The same concentration was used for measurements of EDOTMeOH.

Particles characterization was carried out using dynamic light scattering (DLS). A Malvern Zetasizer Nano ZS instrument equipped with a $4.0 \mathrm{~mW}$ He-Ne laser, operating at $633 \mathrm{~nm}$, at a detection angle of $173^{\circ}$, was used. The intensity-weighted mean hydrodynamic size ( $\mathrm{Z}$ average) and the polydispersity factor were obtained from an analysis of the autocorrelation function. Samples were used as prepared, without filtration at a concentration of $\mathrm{c}=1 \mathrm{mg} / \mathrm{mL}\left(0.49 \times 10^{-6} \mathrm{M}\right)$ in $\mathrm{CHCl}_{3}$ and acetonitrile. The reported values represent the average of the three measurements of each sample, at $25^{\circ} \mathrm{C}$, with an equilibration time of $5 \mathrm{~min}$ before each measurement. Quartz cells were used for all the measurements.

The morphology of the EDOT-PCL thin film was highlighted by atomic force microscopy (AFM) using an NTEGRA Spectra (NT-MDT, Russia) instrument with commercially available silicon nitride cantilevers (NSG10, NT-MDT, Russia). The samples were 
obtained by drop-casting the EDOT-PCL solution in the given solvent at a concentration of $1 \mathrm{mg} / \mathrm{mL}\left(0.49 \times 10^{-6} \mathrm{M}\right)$ on freshly cleaved muscovite mica and were dried at ambient temperature before observation. To allow for uniform evaporation, the samples were kept in a solvent-saturated atmosphere during film formation by using a glass dome that only partially covered them. The resulting topographical AFM images were analyzed using Nova 1.0.26.1443 software.

\section{Results and Discussion}

\subsection{Behavior of EDOT-PCL in Solution}

In order to investigate the properties of EDOT-PCL in solution, and more specifically, to investigate its propensity for SA in solvents with different selectivities and the spontaneous formation of self-assembled structures by direct dissolution, some appropriate techniques were used. Thus, nuclear magnetic resonance spectroscopy (NMR), UV-vis and fluorescence spectroscopy, as well as DLS were chosen as methods sensitive not only to the intrinsic solvent effects but also to those that occur as a result of a change in the solute conformation or structure due to the change in the solvent. Even more specifically, the NMR technique is suitable because it has been extensively used to study the organization and structure of molecular brushes in solution [52], in order to establish polymers' microstructure [53] and to determine polymers' absolute molecular weight [54] and their regioregularity [55]. Solvent-dependent ${ }^{1} \mathrm{H}-\mathrm{NMR}$ studies, conducted to prove the formation of micelles from amphiphilic structures [55,56], were also performed.

The ${ }^{1} \mathrm{H}-\mathrm{NMR}$ and ${ }^{13} \mathrm{C}-\mathrm{NMR}$ spectra, corresponding to the EDOT-PCL macromonomer, which were registered in $\mathrm{CD}_{3} \mathrm{CN}$, and their assignment of proton and carbon signals according to structural formulas, are presented in Figure 1. A detailed discussion of them can be found in Supplementary Materials (SM). By comparing these spectra with previously published data, for which the EDOT-PCL macromonomer NMR registration was performed in deuterated chloroform $\left(\mathrm{CDCl}_{3}\right)$ [42], an increased polarity of $\mathrm{CD}_{3} \mathrm{CN}$ was shown to influence the position of the signals in the ${ }^{1} \mathrm{H}-\mathrm{NMR}$ spectrum, as was expected [57]. Thus, most of the proton signals were upfield-shifted in $\mathrm{CD}_{3} \mathrm{CN}$, as can be seen by comparing to the values registered in $\mathrm{CDCl}_{3}$ (see Figure $\mathrm{S} 1$ and Table $\mathrm{S} 1$ in SM). Following this comparison, it can be seen that the position of the signal that corresponds to the $\mathrm{CH}_{2}$ group (denoted $\mathbf{k}$ ), which is directly bonded to the hydroxyl-end of the OCL chains, was most affected $(\Delta \delta=0.22 \mathrm{ppm})$. This is an expected phenomenon because acetonitrile, in spite of it being a weaker hydrogen-bonding acceptor [58], has a higher polar character in comparison to chloroform and shows a more pronounced solvation ability to the hydroxyl moiety $(-\mathrm{OH})$ situated into the neighborhood of protons $\mathbf{k}$. Moreover, hydrogen bonds of $\mathrm{ACN}$ with the-OH groups in the OCL chain ends were not excluded; these types of bonds have already been reported for phenols and ethanol $[59,60]$. Thus, this environmental modification around protons $\mathbf{k}$, when compared to $\mathrm{CDCl}_{3}$ registration, results in an increased density of the electrons, which could be the reason for the registered shifting. Another important difference, as shown in Figure S1, is the discernible downfieldshifting in the range 6.36-6.38 ppm, which is was assigned to the aromatic $\mathbf{a}$ and $\mathbf{b}$ protons of the thiophene ring. The explanation for this opposite influence of the $\mathrm{CD}_{3} \mathrm{CN}$ on the two different constitutive parts of EDOT-PCL could be found in its specific interaction with the aromatic thiophene ring in EDOT moiety, which significantly differs from the interaction with aliphatic $\mathrm{CH}_{2}$-methylene in OCL repeating units. Thus, if the values of the dipole moments of the $\mathrm{CDCl}_{3}, \mathrm{CD}_{3} \mathrm{CN}$, and EDOT ring are considered (see Table $\mathrm{S} 2$ in $\mathrm{SM}$ ), it can be assumed that the interaction of $\mathrm{CD}_{3} \mathrm{CN}$ molecules with the EDOT moiety is favored compared to $\mathrm{CDCl}_{3}$ molecules. This is due to the higher polar character of $\mathrm{CD}_{3} \mathrm{CN}$, which results in a stronger dipole-dipole interaction with the fused rings of EDOT. If the solute-solvent interaction is taking place more preferentially in the region of the ethylenedioxy ring of EDOT, then it results in the deshielding of the thiophene ring of EDOT, which can explain the modification that was observed in the NMR spectrum of protons $\mathbf{a}$ and $\mathbf{b}$ (Figure S1A). 


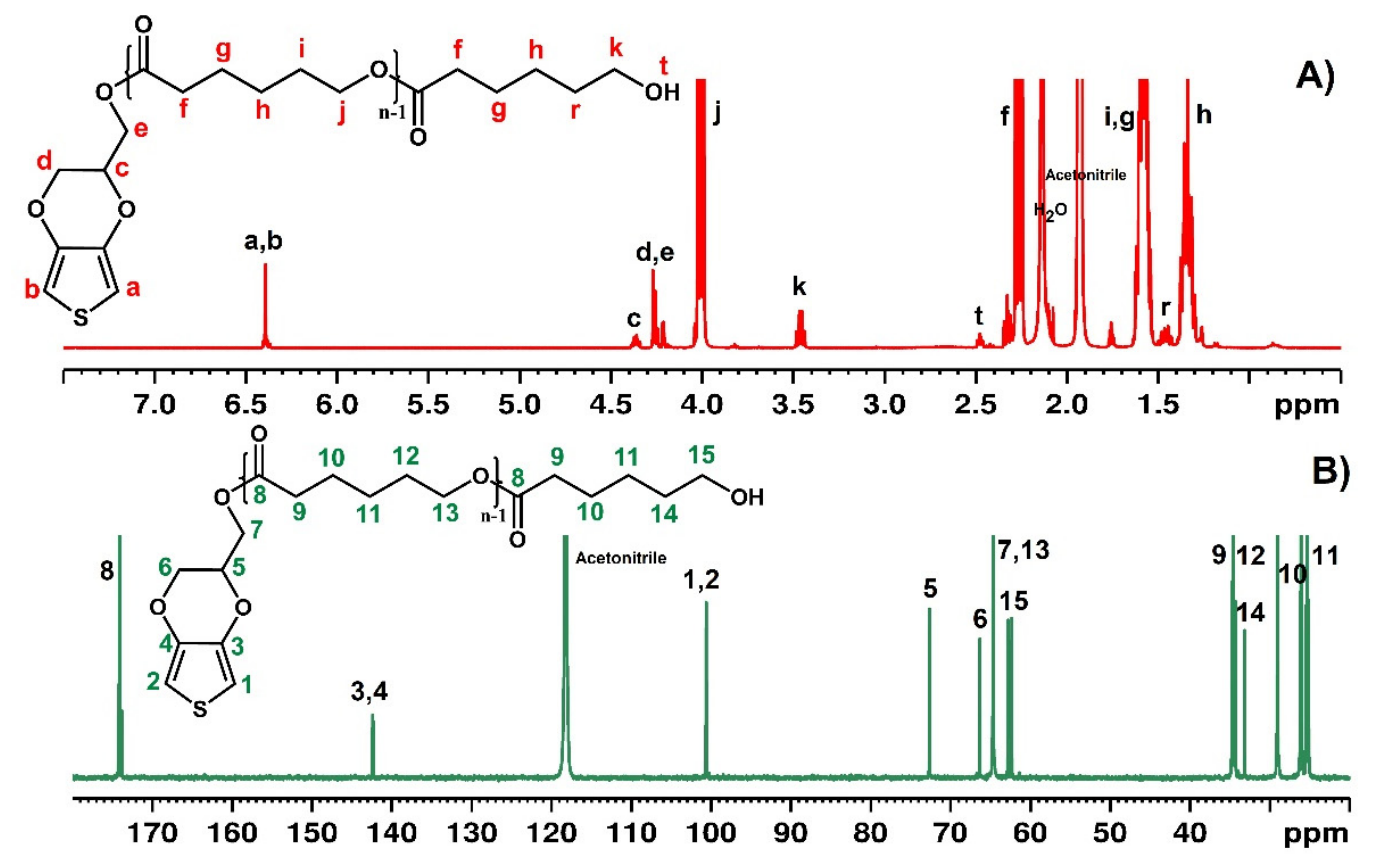

Figure 1. ${ }^{1} \mathrm{H}$ - (A) and ${ }^{13} \mathrm{C}$ - (B) NMR spectra of EDOT-PCL macromonomer in $\mathrm{CD}_{3} \mathrm{CN}$.

Moreover, if the general principle that an increase in solvent polarity leads to a deshielding effect in the fully soluble parts, which results in downfield-shifting, is taken into account, the NMR investigations confirmed the known character of $\mathrm{ACN}$ as a poor/nonsolvent for PCLs [61,62]. Meanwhile, the upfield-shifting of $\mathbf{a}$ and $\mathbf{b}$ aromatic protons in $\mathrm{Chl}$ is striking evidence of the EDOT-PCL intermolecular $\pi-\pi$ stacking of the aromatic segment of the molecule [63] in this solvent, thus suggesting the formation of associated supramolecular structures.

This opposite "upfield-downfield" shifting, observed in a solvent-dependent NMR study of EDOT-PCL, emphasizes a net difference in the interaction of the solvents used with the aromatic, rigid, and planar parts on the one hand and the aliphatic, flexible OCLs on the other hand. It also leads to the idea that, at the supramolecular level, the aromatic and aliphatic parts of EDOT-PCL could be placed in spatially different regions in the solution. As NMR is one of only a few techniques that allow for the determination of the molecular spatial location, due to their intra- and inter-molecular interactions, we made use of the two-dimensional nuclear Overhauser effect spectroscopy $\left(2 \mathrm{D}^{1} \mathrm{H}^{-1} \mathrm{H}-\mathrm{NMR}\right.$ NOESY) variant in order to evaluate the ACN-induced behavior of EDOT-PCL.

Based on the through-space dipole-dipole interaction, NOESY experiments have provided significant information on both the intra- and inter-molecular proximity of protons [64] that have sufficient rotational mobility [65] and which had internuclear distances that were typically $<0.5 \mathrm{~nm}$. This provided excellent insights into the nature of the micelleforming process [65-67], which is applicable in any kind of self-assembled structure, for any geometry, and for any type of constituents [65].

In Figure 2A, which represents the chemical shift region between 1.0 and $4.7 \mathrm{ppm}$ from the 2D NOESY ${ }^{1} \mathrm{H}^{-1} \mathrm{H}$ spectrum of EDOT-PCL in $\mathrm{CD}_{3} \mathrm{CN}$ (see Figure $\mathrm{S} 2$ for the whole investigated range), the identified through-space couplings are marked by blue letters in order to differentiate them from the COSY cross-peaks between the J-coupled protons (noted with black letters), which also appear in the NOESY spectrum. The existence of cross-peaks confirms that magnetization transfer is possible and that there is proximity between the different protons, even transient ones. Moreover, as these peaks are negative, as previously reported [68], they are evidence of fast motion in the solution of the flexible part of EDOT-PCL molecules. It has also been stated that the cross-peaks that are assigned to intramolecular interactions are naturally more pronounced than those for intermolecular 
correlations [65]. In Figure 2A, peaks attributed to $\mathrm{H}_{\mathbf{j}}-\mathrm{H}_{\mathbf{h}}$ and $\mathrm{H}_{\mathbf{f}}-\mathrm{H}_{\mathbf{h}}$ interactions have the highest intensities, and they characterize each OCL-repeating unit's intramolecular behavior. Their appearance is expected so long as the length of one of the PCL-repeating units, calculated from the crystallographic data, is $0.86 \mathrm{~nm}$ [69]; thus, the distance between the $\mathbf{j}$ and $\mathbf{h}$ or $\mathbf{f}$ and $\mathbf{h}$ protons will most likely be in the range $\leq 0.5 \mathrm{~nm}$. With a lower intensity, cross-peaks are also present in Figure 2A and are due to the interactions (intrabut also intermolecular ones) between protons $\mathbf{g}$ and $\mathbf{i}$ and protons $\mathbf{j}$ and $\mathbf{f}$. In the case of intramolecular interactions, the presence of the peak $\mathrm{H}_{\mathbf{j}}-\mathrm{H}_{\mathbf{f}}$ is important because it sustains the possibility of there being a more collapsed OCL chain in a marginal ACN solvent, thus allowing $\mathbf{j}$ and $\mathbf{f}$ protons to be placed at a distance of around $0.5 \mathrm{~nm}$. The presence of the peak $\mathrm{H}_{\mathrm{e}}-\mathrm{H}_{\mathrm{j}}$ is important for sustaining our claim of EDOT-PCL SA, and thus for the presence of EDOT and OCL in different spatial areas.
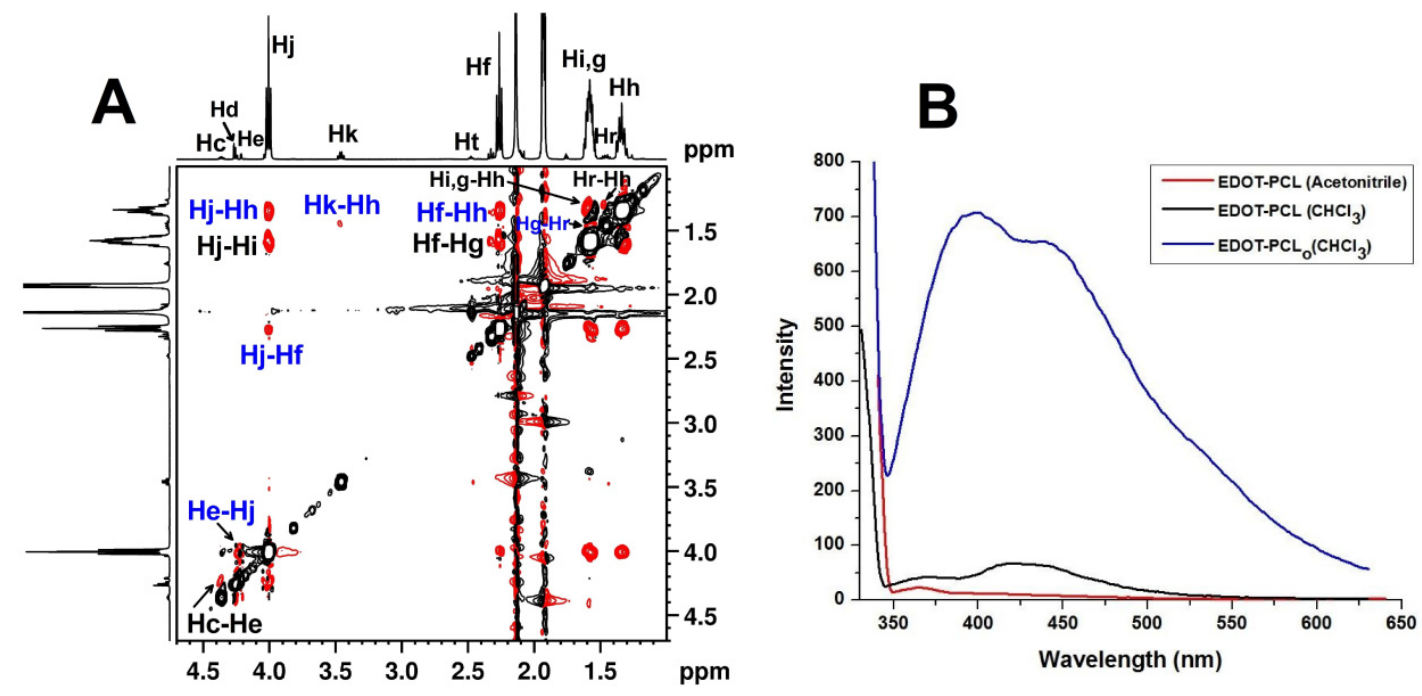

Figure 2. (A) 2D NOESY ${ }^{1} \mathrm{H}-{ }^{1} \mathrm{H}$ spectrum of EDOT-PCL in $\mathrm{CD}_{3} \mathrm{CN}$ (0-4.7ppm range). (B) Fluorescence spectra of EDOT-PCL macromonomer and its oligomerized form (EDOT-PCL $)$ in the used solvents at concentrations of $1 \mathrm{mg} / \mathrm{mL}$, $\left(0.49 \times 10^{-6} \mathrm{M}\right)$, and $\lambda_{\text {excit }}=\lambda_{\max }$ abs (see Table S3).

This is the only peak that is specific to the interaction between a proton that is reminiscent of the initiator and a proton that belongs to the OCL chain. Its existence proves the fact that this flexible part from the EDOTMeOH initiator shares the same space/area with the OCL chains, e.g., the core of a micelle-like particle or a borderline space between the core and the shell of these supposedly formed micellar particles. Moreover, there are presently no peaks characterizing interactions between proton $\mathbf{e}$ and any of the nearest $\mathbf{c}$ or d protons in the EDOT moiety. This is also evidence for a different placement in the space of the aromatic heterocycle.

In completion of the NMR data, photophysical properties of EDOT-PCL in the same solvents were investigated, as well. It is known that such analyses mirror the self-assembly phenomena in solution [70-73]. Figure S3A presents the traces of the absorption spectra of EDOT-PCL in the two investigated solvents at a concentration of $0.49 \times 10^{-6} \mathrm{M}$. This concentration was maintained the same for all the other investigations (DLS and AFM). The traces in Figure S3A show a vibronic aspect and a high absorbance. It was demonstrated that these are due to a high value of the solution concentration. When the registration was performed at a concentration of $0.245 \times 10^{-6} \mathrm{M}$, the appearance of the curves becomes smooth (Figure S3B) and without peaks position modification in comparison to those registered at the higher concentration. In the two investigated solvents, $\lambda_{\max }$ abs of the peak with the highest absorbance appears in almost the same position $(254 \mathrm{~nm}$ in ACN and $257 \mathrm{~nm}$ in Chl). 
The bimodal curve in ACN has a similar shape as a reported TEMPO-containing EDOT compound (also obtained from EDOTMeOH), which shows $\lambda_{\text {max }}$ abs at $256 \mathrm{~nm} \mathrm{[74]}$ and of bare EDOT, registered in ethanol [75], with the two absorption peaks at $215 \mathrm{~nm}$ and $243 \mathrm{~nm}$, respectively.

Moreover, in Figure S3C, the UV-vis absorption traces of the EDOTMeOH, used as an initiator in the synthesis of EDOT-PCL, and registered in the same solvents, presented shapes that were similar to those of EDOT-PCL, with $\lambda_{\text {max }}$ abs values (Table S3) being practically unchanged for ACN and with only a $5 \mathrm{~nm}$ red-shift for Chl.

The conclusion can be drawn that the introduction, through an ester linkage, of the OCL chain at the third position of the EDOT fused rings had practically no influence on its UV-vis absorption properties, and as expected, that EDOT moiety was the only absorbing/emitting (Figure 2B) component of EDOT-PCL. A slight shifting of the $\lambda_{\text {max }}$ abs, of about $3 \mathrm{~nm}$, was observed in the traces of the two solvents for EDOT-PCL (Figure S3A), and this confirms the previous claim that the absorption phenomenon is insensitive to the solvents' polarity change and only affects the excited state [76]. Figure 2B shows the changes in the photoluminescence behavior of EDOT-PCL, which can be correlated with the change in the solvents' dielectric constant. Thus, the two traces corresponding to the $\mathrm{Chl}$ and ACN solutions, at identical concentrations, which are non-symmetrical, bimodal, and broad, cover a range of approximately $200 \mathrm{~nm}$ and have emission maxima $\left(\lambda_{\max } \mathrm{em}\right)$ placed between the violet-blue and blue regions (365-430nm). A $\lambda_{\text {max }}$ em hypsochromic shift of $5 \mathrm{~nm}$ for the first emission maximum and $35 \mathrm{~nm}$ for the second was observed when the solvent polarity increased from Chl to ACN (Table S3 in SM). This shift was accompanied by a decrease in the intensity of the fluorescence. In addition, the magnitude of the low-energy peak increased in Chl. However, it is also important to emphasize that the fluorescence traces of the EDOTMeOH initiator, which were registered in the same solvents, were monomodal but broad and non-symmetrical (Figure S3D), with a blue-shifted $\lambda_{\text {max }}$ em at $350 \mathrm{~nm}$ and $325 \mathrm{~nm}$ (see also Table S3) compared to EDOT-PCL. The possible explanations for all phenomena described above are as follows: (i) the blueshifting of $\lambda_{\text {max }}$ em registered in the polar ACN solvent could be due to the stabilization of the ground state of EDOT-PCL, which has an increased polar character than the excited state; (ii) the bimodal shape and presence of the red-shifted peaks in both the investigated solvents, (the last one being a mark for the formation of the nanoparticles/micelle-like particles $[55,72,77])$, could be proof of the self-assembling nature of EDOT-PCL in the solution; (iii) the increased values of apparent hydrodynamic diameter $\left(\mathrm{D}_{\mathrm{h}}\right)$ of the selfassembled structures in ACN in comparison with those formed in Chl, experimentally determined (vide infra) could be the reason for the observed fluorescence intensity decrease in this solvent. This behavior followed the well-established phenomenon of the dependence of fluorescence intensity on particle size [7,55]. In general, the results obtained from the fluorescence measurements lead to the conclusion that particular interactions with each of the solvents used in OCL chains (as a major component of EDOT-PCL) as well as OCL-adopted conformation (extended in Chl or collapsed in ACN) are two of the most influential factors on this property. Additionally, specific EDOT planar geometry and peculiar inter-rings interaction besides their relative orientation, which is driven by the ring aromatic nature and by the $\mathrm{S}$ and $\mathrm{O}$ heteroatoms presence, can contribute to the noticed behavior [78,79]. In addition, the presence of OCL, as a substitute in the third position of the EDOT fused rings, has no negative impact on the $\lambda_{\max }$ em values when compared to that of the starting, non-assembled EDOTMeOH. In a similar manner to what was previously reported for PEG [75,80], OCL from the shell of micellar particles works as an electronic shield to preserve and protect the fluorescence of EDOT in the core.

In addition to the NMR measurements and to the photophysical properties that only suggested the formation of the EDOT-PCL self-assembled structures, DLS can be used as a technique that "senses" the presence of such entities and more certainly probes their formation $[7,25]$. DLS traces, as intensity-weighted distribution of $D_{h}$, shown in Figure S4A, are multimodal in both solvents (bimodal in $\mathrm{Chl}$ and trimodal in $\mathrm{ACN}$ ), and this emphasizes 
the possible concomitant presence of colloidal particles of various sizes or clusters formed by them in solution. In both solvents, most of the formed structures (approximately $88 \%$ ) had a $D_{h}$ of $184 \mathrm{~nm}$ in Chl and $196 \mathrm{~nm}$ in ACN. The higher value of $D_{h}$ in ACN could be due to the fact that PCL has a collapsed conformation. Consequently, a higher number of EDOT-PCL molecules, exposing the fused rings to ACN solvent, should assemble together in order to attain colloidal stability. The largest values of $4800 \mathrm{~nm}$ in Chl and $5500 \mathrm{~nm}$ in ACN could be indicative of the eventual presence of particle clusters. These high values can also be due to the presence of particles that do not have a spherical/globular shape because of the limitations of the DLS technique. In general, the information given by DLS measurements should be viewed with utmost care. Thus, an argument for the limitations of the DLS result, is also represented by the traces shown in Figure S4B. This figure shows the traces as volume-weighted distribution of apparent $D_{h}$, which is bimodal for both solvents. For the solution in Chl, the apparent $D_{h}$ has almost the same values as those found in intensity-weighted measurement. The only difference is referring to the volume contribution of the particles with higher $D_{h}$, which is increased as compared to that obtained in the same solvent in Figure S4A. For the ACN solution, the peaks which in intensity-weighted representation appeared at higher values (196 and $5400 \mathrm{~nm})$ are missing in trace in Figure S4B. This missing suggests that the volume contribution of these particles is also negligible. In both Figure S4A,B, the smallest values of the apparent $D_{h}$, of only $4.3 \mathrm{~nm}$ and $3.13 \mathrm{~nm}$, respectively, which were determined in $\mathrm{ACN}$, could be due, hypothetically, to the presence of particles that are formed from only several associated molecules or due to unimolecular micelle-like aggregates. In order to roughly decipher this aspect, the theoretical diameter of gyration $\left(\mathrm{D}_{\mathrm{g}}\right)[81]$ of $2.28 \mathrm{~nm}$ was obtained, based on the value of the oligo- $\varepsilon$-caprolactone's radius of gyration $\left(\mathrm{R}_{\mathrm{g}}\right)$ [82]. This value resulted from the calculations that are included in the SM. If the collapsed conformation of PCL in the marginal ACN solvent is accepted, the colloidal particles of only 4.3 and $3.13 \mathrm{~nm}$ would be considered to be micelle-like particles formed from more than two EDOT-PCL molecules.

\subsection{Surface Morphology Analysis of EDOT-PCL Thin Films}

Different microscopy techniques are commonly used to visualize the morphology of solution-based films, even if there is a clear distinction between the self-assembled structures in the solution that could be affected by their transformations during solvent evaporation and film-forming. This is because such a process involves both the physical properties of the support used and the colloidal stability of the solution-formed particles. Thus, the presence of particles with variable sizes (with an average lateral width of around $200 \mathrm{~nm}$ ) as a dense, uniformly scattered network, as shown in the AFM images in Figure 3, confirm that the self-assembled structures of EDOT-PCL in Chl, detected by DLS, are round in shape. The particle shapes and the AFM appearance are evidence of the formation of micelle-like structures in the solution, which probably have less soluble EDOT moiety as a core (see Table S2 for solubility parameter values) and OCL as protecting shell. These particles are expected to have enhanced stability as the OCL chains are more probable into a stable, extended conformation mediated by the hydrogen-donor character of Chl (its acidic nature), which generate favorable hydrogen-bonding interactions (cross-associations) with the nucleophilic ester groups of basic nature in OCL [62]. It appears that, from the point of view of chain conformation, the interaction of OCL with Chl has a similar result to that of the water interaction with PEG, which was explained in detail in our previous report [55]. 

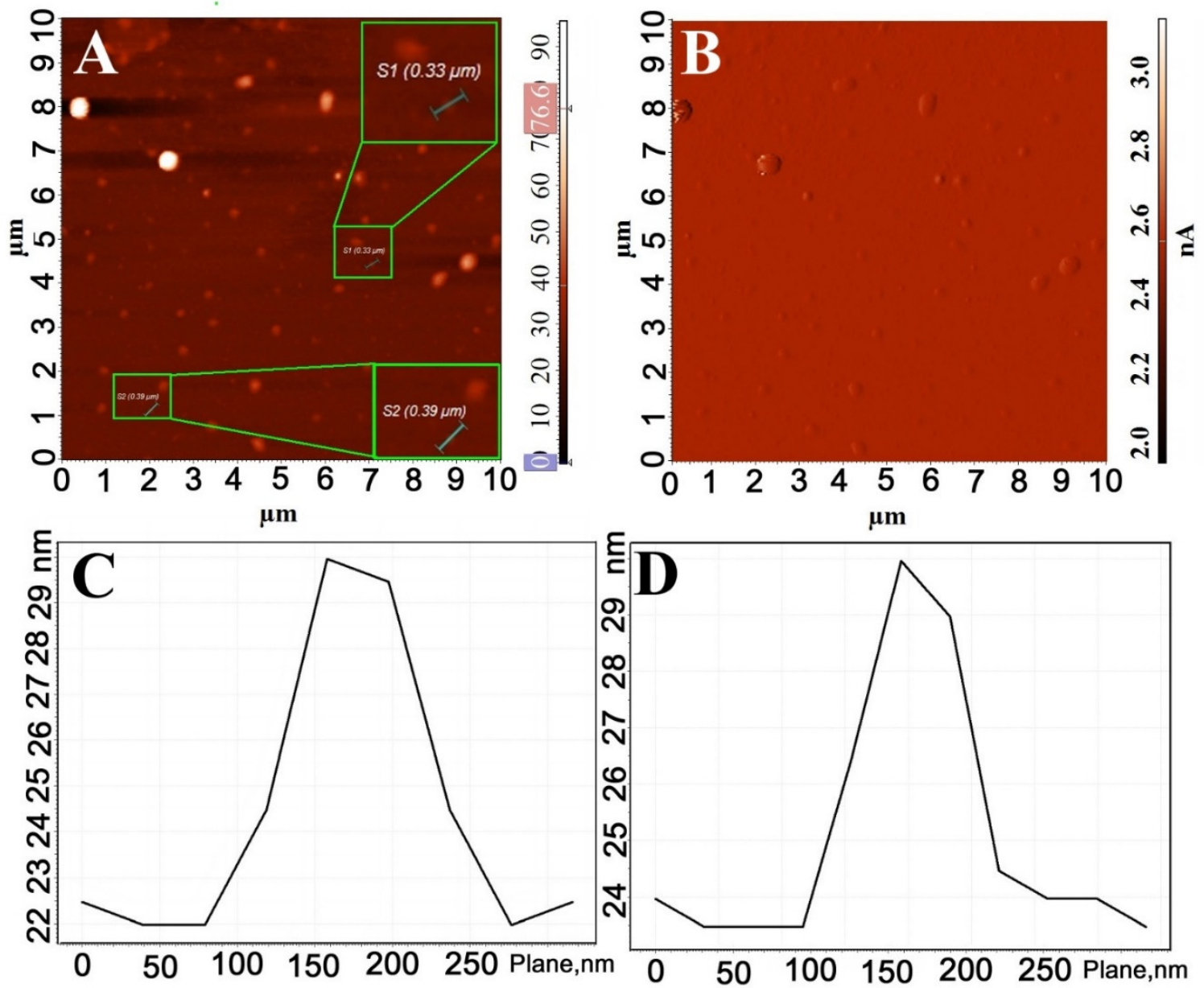

Figure 3. (A) AFM height image of the round-shaped particles formed by drop-casting an EDOT-PCL solution in Chl; (B) AFM amplitude image; (C,D) cross-sectional analysis of the particles shown in magnified insets in (A): (C) S1 section and (D) S2 section.

The net selectivity of $\mathrm{Chl}$ for OCL endows the system with increased segregation power. This is because, besides solvophobic/solvophilic interactions, the $\pi-\pi$ interaction of the EDOT rings in the core of the assembled structures are also favored due to the thiophene rings' propensity for $\pi$-stacked dimer/oligomer formation through intermolecular interactions [83].

The EDOT-PCL particles in the dry state, which are discernible in the AFM images in Figure 3, are larger in size than the values of $D_{h}$ obtained in the solution from the DLS measurement. This could be caused by the fusion of the smallest particles during solvent evaporation. There is also a significant difference between the width and height of these round structures; the height is very small $(5-8 \mathrm{~nm})$ compared to the width (see Figure 3C,D). Thus, from a geometric point of view, they are similar to disk-shaped particles. The asymmetry of the cross-section can be attributed to particle collapse, which is due to the deflection induced by solvent evaporation. This is concomitant with its interaction with the support during film formation. Moreover, it is important to note that no characteristic forms of OCL crystallization appeared during Chl evaporation in any of the investigated areas.There were several reasons for this. As was stated before, mica is not an appropriate support to study PCL crystallization [84] because, due to the difference in the polarity between Chl and hydrophilic mica, when a solution of PCL in Chl was spun onto it, the hydrophobic PCL was dewetted thereon, thus forming droplets in order to minimize the free energy [85]. It has been explained that when such droplets form, their high surface tension prevents the crystallization of semicrystalline polymers; thus, it is 
difficult to make them have a lamellar morphology [86]. In our particular case, besides there being a reason similar to that mentioned above, the EDOT moieties' intermolecular $\pi-\pi$ aromatic interaction, in the inner core of the micelles, could also be an effective hindrance of the crystallization of the OCL shell, as was observed by others [87]. The morphology of the thin film obtained from the EDOT-PCL chloroform solution on mica is in stark contrast to that obtained previously for another PCL-containing macromonomer (2,5-dibromo-1,4-phenylene-PCL substituted) in Chl [88], which formed flat-on lamellae after spin-coating on a hydrophilized $\mathrm{SiO} 2$ surface (without any melting and recrystallization). This behavior was attributed to the strong interaction of the PCL hydroxyl end groups with the substrate.

This comparison supports the conclusion that not only the processing conditions but most importantly, the structural peculiarities (position of the functional group — the end group—vs. "in chain" group [26] —and the type of the group) are also decisive aspects of the supramolecular organization of the functionalized oligo/poly(e-caprolactone) in thin films.

A rich and sophisticated morphology was obtained when the drop-caste film was obtained from the ACN solution (Figures 4 and 5, Figures S5-S7). This is further evidence that EDOT-PCL behaves as a "block molecule". This term denotes monodisperse $[47,48]$ or slightly polydisperse [49] flexible systems that are end-capped with aromatic fragments, whose SA can be considered to be analogous to that of linear block copolymers (BCPs) constructed with one block that is significantly stiffer than the others [48]. In this context, it is important to highlight some significant aspects that are related to the self-assembly of block copolymers [89], especially the semicrystalline block copolymers that contain at least one crystallizable block. This is because crystallizable OCL is the major component of EDOT-PCL.

It was experimentally confirmed that, by substituting a block in a coil-coil BCP with a crystallizable one, the SA proceeds on a distinctive path, which leads to a particular behavior in the solution and in bulk [89-92], in addition to other complicated phenomena during thin film formation on a solid support [89,92]. Various interrelating parameters (such as solvent "quality" / selectivity, solution concentration, melting and crystallization temperature, the support's surface tension, polymer-support interaction, and film thickness, to enumerate only a few) are involved in all of these circumstances [20,89-93]. This is because, besides the microphase separation of incompatible building blocks of BCPs, crystallization arises as a competing/complementary SA driving force, which influences its phase structure development. The competition between the two-phase transitions leads to confined, templated, or breakout crystallization modes [20,89,91,92].

In particular, self-assembling in the solution of semicrystalline BCPs is a very important topic [89-92,94] because micellar structures, which form when such BCPs are exposed to energetically unfavorable conditions for the crystalline block (a non-selective, marginal solvent), generally tend to form nanostructured morphologies with low curvatures (cylinders, ribbons, and platelets) [95]. This gives rise to nanoconfined systems, which significantly affect various stages of crystallization, thereby increasing complexity and concomitantly and dramatically changing the properties of these materials [20,92].

Moreover, the interplay between microphase separation and crystallization in the micellar systems of BCPs is also important in the context of solution-based thin film formation [96]. This is because the morphologies obtained in thin films (also 1D nanoconfined systems) are often driven by self-association in the solution $[97,98]$.

All of the briefly mentioned aspects above touch on the behavior of EDOT-PCL, which in an ACN diluted solution, form micelle-like particles, with a crystallizable OCL as the core and rigid planar cycles in the shell, as was suggested by the NMR, UV-vis, fluorescence, and DLS results. In the AFM investigated area, as shown in Figure 4 and Figures S5 and S6, a co-existence of spherical-, straight rod- and helical rod-like morphology can be seen, with a small incidence of the first two in comparison to the helical rods, which appeared more frequently. 
There could be many reasons for the mixed morphology of the structures, which differ in the interfacial curvature that appeared, but most likely is the OCL polydispersity index $[99,100]$.
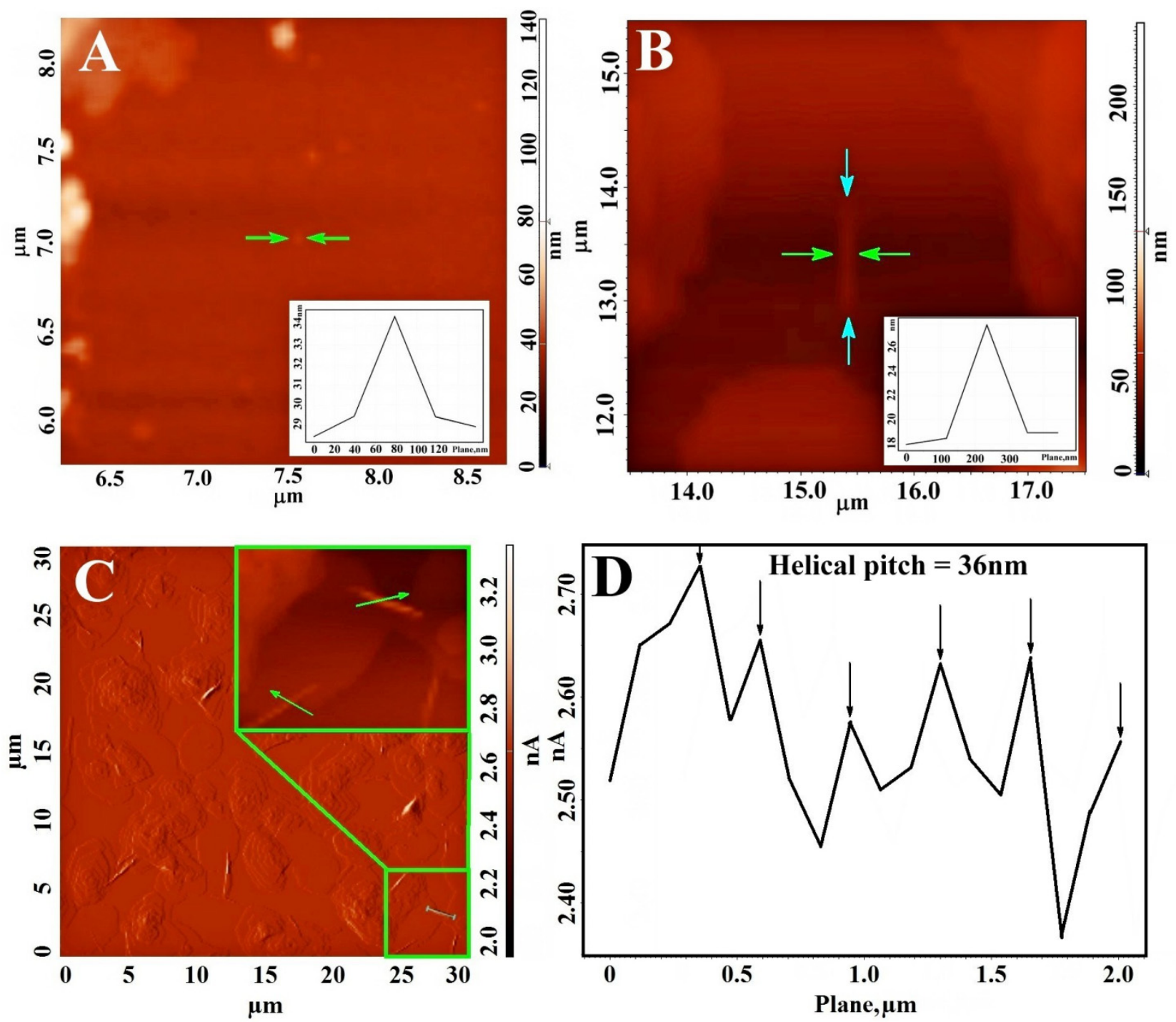

Figure 4. (A) AFM height image of round-shaped-like particles formed in the thin film of EDOT-PCL, obtained from its ACN solution - the inset shows a cross-sectional analysis of the particle's horizontal line and marked by arrows); (B) AFM height image of a straight rod with the length marked by the blue arrows-the inset shows a cross-sectional analysis of the rod's horizontal line and is marked by the green arrows; (C) AFM amplitude image evidencing the formation of the helical rods - the inset is the magnified marked area showing a high aspect ratio of helical rods with the arrows indicating both leftand right-handedness; (D) cross-sectional analysis that provides an average value of the helical pitch. 


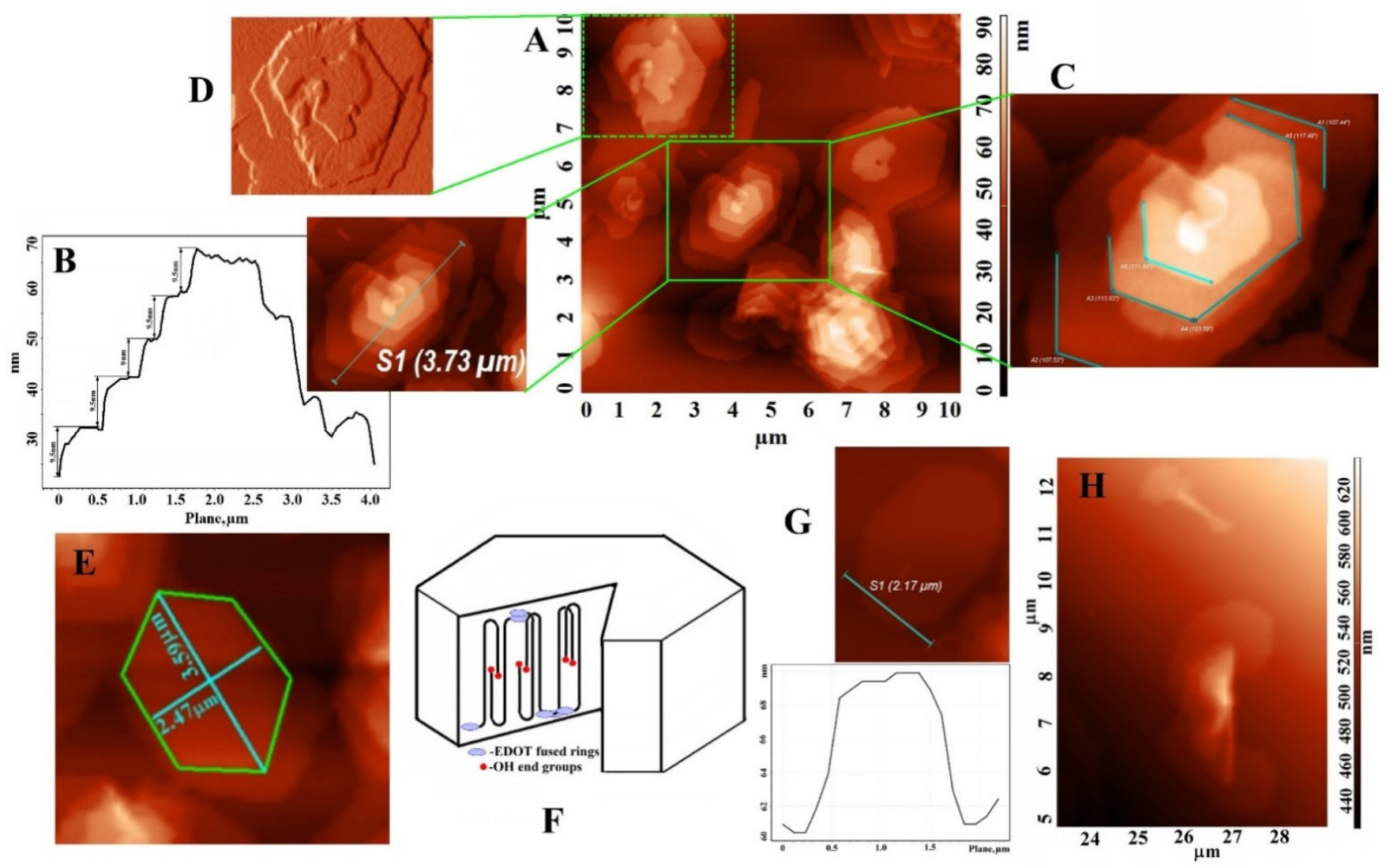

Figure 5. (A) AFM height image of EDOT-PCL platelets as almost perfect hexagonally shaped single crystals (SCs); (B) AFM height image of a multi-lamellar SC and its cross-sectional analysis, which shows individual lamellae thicknesses; (C) angle values between two consecutive $\{110\}$ faces and between the $\{110\}$ and $\{100\}$ faces of SCs; (D) AFM amplitude image showing the usual PCL SC lamellae's striations; (E) the aspect ratio of the perfect six-sided facetted EDOT-PCL SC; (F) schematic representation of possible OCL chain-folding, thereby forming the hexagonal lamella of EDOT-PCL SC; (G) AFM height image and cross-sectional analysis of a non-perfect mono-lamellar SC; (H) AFM height image showing straight and helical rods breakout crystallization and the starting of 2D platelet formation.

We attributed the formation of such structures, which have thermodynamic stability that is high enough to retain the shape after solvent evaporation, to EDOT-PCL microphase separation in the ACN, which was driven by the solvophobic/solvophilic interactions, which in this case dominated the structural self-organization. Our claim is supported by the large difference between the affinities of the structural components of EDOT-PCL in relation to ACN. Besides the recognized marginality of ACN for PCL [62], the high miscibility of EDOT with ACN can be seen because both the dipole moment and solubility parameters of EDOT (see Table S2) are simultaneously closer to those of ACN [101], as compared to OCL. The fact that a spherical micellar shape is preserved in the films (Figure 4A) is proof that solvophobic interactions overwhelm crystallization ordering in the micelles' inner core and that crystallization could take place in the confined spaces formed by them [89,92]. This hypothesis is also supported by the fact that confinement reduces the crystallization ability of the polymer [89], which, for PCLs functionalized with bulky end groups, is significantly affected [102]. Additionally, it is well known that the core of the 3D-confined spherical micelles has the lowest degree of crystallinity, as compared to the 1D and 2D types of confinement geometries [90,91].

At this stage of our research, it is not possible to clearly state whether the core of the round micelles, formed at room temperature, is amorphous (melted) or has a degree of crystallinity. In a future study, for example, through DSC measurements in solution, the 
melting and crystallization temperatures of OCL could be determined in order to clearly confirm its state at room temperature.

However, it is reasonable to suppose that, due to confinement, the values of those parameters could be significantly lower than those for EDOT-PCL in bulk $\left(\mathrm{T}_{\mathrm{m}}=50^{\circ} \mathrm{C}\right.$ and $\mathrm{T}_{\mathrm{C}}=27^{\circ} \mathrm{C}$ ) [42]. This is similar to what was reported previously for other bulky end-groups functionalized PCL [102].

Straight rod-like structures (Figure 4B), whose presence is very likely in the solution (the DLS trace in Figure S4A is multimodal), could have formed as a consequence of the propensity of crystallizable OCLs to induce low curvature structures, in this case, the 1D rods with lower energy than spherical micelles. These rods are no more than $1 \mu \mathrm{m}$ in length and have a width of $250 \mathrm{~nm}$ and a height that varies from 9 to $10 \mathrm{~nm}$ (Figure 4B). Even if no visual evidence has been found in AFM images, the possibility of the formation of this type of entity by the spherical particles during solvent evaporation should not be completely ruled out.

Thus, it could be possible that, during solvent evaporation, the EDOT-containing shell of the spherical micelles' corona shrinks and thus occupies less space at the surface of the OCL core. Consequently, the spherical micelles may become unstable, and objects with a smaller overall curvature (rods) could form.

Interestingly, as compared to round particles and straight rods, there is currently a large number of visible helical-rod-shaped supramolecular assemblies with left- or righthandedness (Figure 4C), and with a width of approximately $250 \mathrm{~nm}$, a length of around 2.5-3 $\mu \mathrm{m}$, and a helical pitch of $36 \mathrm{~nm}$ (Figure 4D). The helical structure is a sophisticated, ubiquitous motif that is found in biological systems, the conformation of which is related to the chirality that is caused by supramolecular assembling. In some synthetic systems, helical supramolecular assemblies can be formed from highly anisotropic achiral amphiphiles, which contain rigid aromatic moieties [71,103-106], without external symmetry-breaking inducing factors. In all these cases, but especially for block copolymers [71,105,107], the occurrence of symmetry breaking is subtle and depends on both the molecular structure and external environmental factors.

Thus, helical assembly formation, caused by the coiling of cylindrical objects (micelles, fibrils) $[105,107]$, was ascribed, in principle, to the introduction of an attractive interaction along their periphery, allowing for efficient contact between the surfaces of neighboring loops along the helix. There may also be other factors that could have, synergistically, contributed to the formation of the helix.

In the current system, from the three types of interactions at play during film generation, i.e., solute-solvent, solute-support, and solute-solute, the last two could be responsible for the coiling of the rod-like structures that are longer than $1 \mu \mathrm{m}$ in a helical shape. Thus, dispersed SA structures, when deposited, wet the mica surface by exposing the EDOT rings of their shells to the surface of the support. By evaporating the ACN solvent, the solute-support interactions are increased, and in this way, the EDOT moieties from some of the EDOT-PCL molecules could be "stuck" to the support. There is a favorable phenomenon of complexation between $\mathrm{K}^{+}$ions that naturally exist on the mica surface and the ethylenedioxy ring in EDOT, which could promote the aforementioned sticking. Such an interaction, recalling the high affinity of PEG to mica [85], could be strong enough to induce surface tension which causes helical twisting of the straight rods. The intermolecular, directional $\pi-\pi$ stacking of aromatic EDOT rings could contribute to this bending through an anisotropic alignment of chromophores that concomitantly stabilize the formed loops. Thus, rod-like helical structures were caused by the synergy of factors that functioned as symmetry-breaking during solvent evaporation, such as the geometric shape and length of supramolecular structures, surface characteristics of the support, ion complexation, and $\pi-\pi$ stacking interactions.

All the structures described above are metastable and "frozen" intermediate morphologies that "talk" about the events that took place during the formation of the EDOT-PCL film from the ACN solution. They also provide a clue to understanding the phenomena 
behind the formation of lamellar 2D structures. As Figure 5, Figures S6 and S7 show, most of these structures, which abundantly populate the film's surface, have the characteristic shape of PCL single crystals (SCs).

Under various conditions, it is well established that PCL tends to form six-sided hexagonal crystals [108]. The techniques used for SCs production contain several steps, they are time-consuming, and they are generally very elaborate. For instance, freestanding PCL SCs have been obtained from solution by isothermal crystallization [109,110], by selfseeding $[110,111]$, or by nanoprecipitation methods [112,113], and they were also formed at the interface with a solid support caused by isothermal crystallization from the melted PCL thin films [114,115]. The only PCL SCs obtained by solvent-evaporation-induced crystallization were those at the interface of two immiscible liquids [116]. To the best of our knowledge, no PCL SCs obtained in thin films on a solid support through simple evaporative crystallization from the solution at room temperature have been reported before. In Figure 5, this type of structure is as obvious as in Figure S7, which shows AFM micrographs of $30 \mu \mathrm{m} \times 30 \mu \mathrm{m}$; the areas marked in green are extended and explained in Figure 5. They are multi-lamellar, as in Figure 5A, or mono-lamellar, as shown in Figure 5G (the expanded area from Figure S7B). They are almost geometrically regular and are placed in a flat-on fashion in relation to the support surface. Generally, this type of lamellar orientation is the preferred one for thinner films of semicrystalline polymers [92], while for linear PCLs, it was observed in crystal growth in molten-state ultrathin films [114]. It is common that the film thickness can be adjusted by the concentration of the solution used for casting [89]. As we used to process our films, a concentration of the solution with a value comparable to that of the linear PCLs, which formed films with thicknesses ranging from $1 \mathrm{~nm}$ to $200 \mathrm{~nm}$ [114], it can be assumed that the thicknesses of the EDOT-PCL films, whose morphology is shown in Figure 5, Figures S6 and S7, does not exceed the upper limit of the mentioned range.

However, an uneven thickness of films can also be seen in these figures. As can be observed in Figure 5A, the SCs with micrometric lengths have the usual PCL lamellar morphology, with large base platelets that are covered with several lamellae as hexagonal terraces, which grow from a screw dislocation $[109,110,112,115,117]$. The thickness of individual lamellae is around $9-10 \mathrm{~nm}$, as was obtained from the measurement of the cross-section trace shown in Figure 5B, which is typical for linear PCL SCs [117]. A similar thickness value was also detected for monolamellar SC presented in Figure 5G. Defined as one of the most important types of defect in polymer structures [118], the screw dislocations found in both PCL-containing linear and branched architectures [110,112,117,119] forbid the crystallographic coherence between successive layers, which give rise to spectacular rotations that are always associated with a pyramidal habit, as can be seen in the bottomright corner of Figure 5A. These screw dislocations have been attributed to different factors [120], but as structural factors, the non-planarity of the ester group carbonyl in the PCL repeating units and the effect of chain ends [118] (especially bulky ones) have been cited as the main reasons.

PCL SCs are constituted by four $\{110\}$ and two $\{100\}$ growth faces, with theoretical values of angles between two consecutive $\{110\}$ faces and between the $\{110\}$ and $\{100\}$ faces of $113^{\circ}$ and $124^{\circ}$, respectively $[117,119]$. Through AFM measurements, the values of both types of angle were determined for the three layers of the hexagonal lamellae of EDOT-PCL (Figure 5C). For the angle between the $\{110\}$ and $\{100\}$ faces, the value of $123.59^{\circ}$ was very close to the theoretical one; for the angles between two consecutive $\{110\}$ faces, the values only slightly deviated from $113^{\circ}\left(113.03^{\circ}\right.$ and $\left.111.9^{\circ}\right)$. It is worth noting that similar angles values were reported for linear PCL with a degree of polymerization of 17 [117] and for a star-branched structure with PCL arms having a degree of polymerization of 10 [119]. These structures had a degree of polymerization for PCL close to that of EDOT-PCL.

The growth faces sectoring of the SC lamellas is partially visible in the AFM amplitude micrograph in Figure 5D; it is clear enough to attribute this, with certainty, to the existence of the six crystallographic faces of EDOT-PCL SC. Moreover, in the same figure, the 
striations that are typical of PCL SCs [121], running from the center to outwards, give an evident contrast and reveal the different sectors. Surface striations are common features for both linear and branched structure-derived PCL SCs [117,119], which have received various explanations. They have been attributed to the presence, in the PCL SCs, of microcrystals with a nano-order size that was oriented along the growth direction [110], or they originated from the non-planar crystal structure [122].

The aspect ratio of the SCs, defined as the ratio of the value of the long axis $\left(l_{b}\right)$ and the short axis $\left(l_{a}\right)$, is an important SC parameter, and provides an indication of the crystal growth rate along these axes. The $\mathrm{l}_{\mathrm{b}}$ and $\mathrm{l}_{\mathrm{a}}$ values are given in Figure $6 \mathrm{E}$ (the expanded area from Figure S7A) for an almost perfect six-sided and facetted EDOT-PCL SC, which resulted in a shape factor of 1.45; the latter characterizes a PCL SC that is less anisotropic than the one resulting from the linear PCL with a degree of polymerization of 17 . This was obtained by isothermal crystallization from the n-hexanol and had a shape factor of 2 [117].

On the issue of the formation of semicrystalline polymers SCs, they resulted from the bottom-up self-assembling process of crystallization [89], involving polymer chains folding back and forth within the lamellae [116]. By using the information for the individual lamella thickness given by the AFM height scanning profile in Figure 5B,G (an average value of $9.5 \mathrm{~nm}$ ), combined with the degree of polymerization of 16.5 for extended OCL length [42], and considering the PCL unit cell parameters [69,117], the number for nonintegral chain folding was 0.5 . We attempted to develop an idea about the arrangement of the EDOT-PCL chains inside the lamellar SCs using this value, and these are represented in the sketch in Figure 5F. This drawing, therefore, shows hexagonal lamella that was formed by non-integral, once-folded OCL chains with adjacent re-entry. We considered this arrangement to be more probable, in comparison to a tilted extended-chain crystal [123], motivated by the high affinity of the EDOT ring to the mica support and by the preference of OCL (in itself an amphiphile [69]) to migrate towards the film's surface from the ACN marginal solvent. Thus, it exposed its aliphatic part towards the film's surface but kept the $\mathrm{OH}$ polar hydrophilic chain ends inside the solution for a longer period of time during solvent evaporation.

Hypothetically, interchain hydrogen bonding has also been suggested to be ideal in the solid state.

It is obvious that all of the above described and characterized crystalline 2D lamellar structures derived from the SA structures formed in the solution. Their formation in the film was mediated by ACN evaporation and the EDOT-PCL interaction with the hydrophilic mica support. These two basic phenomena conducted modification in the corona of micelle-like SA structures that were formed in the solution. Such modification most probably triggered the alteration of the micellar structures, leading to further morphological transitions toward organized structures of the 2D lamellar SCs into the new confined space of the film. In fact, the segregation strength of the system in the solution is affected by ACN evaporation, and OCL breakout-like crystallization is possible, which disrupts the micelle core, leading to lamellar SCs [91]. In support of this statement, the AFM image presented in Figure 5H (the expanded area from Figure S7C) shows the obvious breakoutlike transformation of the straight and helical rods in addition to the development of crystal growth front of the 2D platelet's formation. At this point, it could be speculated that the multi-lamellar structures could be formed by rod transformation, while an almost oval, lessdefined mono-lamellar structure (as is presented in Figure 5G) derived from the spheroidal micelles. Moreover, in Figure S7D, the green arrows mark the presence of rods, especially helical rods, in the immediate neighborhood of the hexagonal multilayered EDOT-PCL SCs; the image shows a "frozen" stage of such rods, which coalesce during solvent evaporation and film formation and their transformation into a more thermodynamically stable SCs. It could be assumed that, in the case of EDOT-PCL, as is the case for other microphaseseparated asymmetric diblock copolymers [124], a structural relaxation of OCL takes place during solvent evaporation, inducing disintegration of the microphase separated structures, thus allowing for breakout crystallization and the formation of SCs. In view of all these 
phenomena, the role of the ACN solvent should not be overlooked because it was reported that a poor solvent could function as a nucleating agent able to induce PCL ultrathin film crystallization [84].
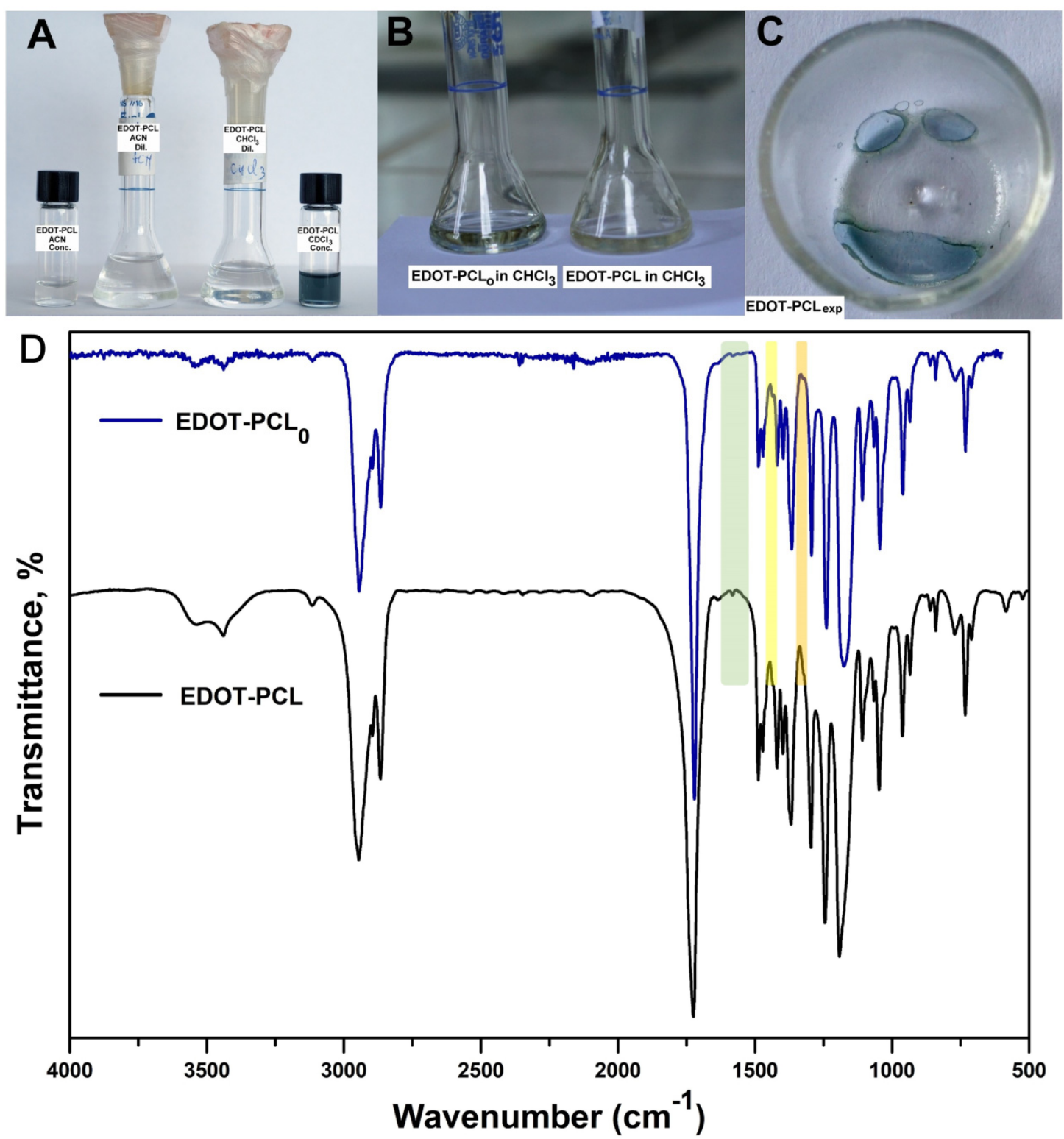

Figure 6. (A) (From left to right): the EDOT-PCL in an ACN concentrated solution, in an ACN diluted solution, diluted EDOT-PCL in Chl, and very concentrated $\mathrm{CDCl}_{3}$ solution of EDOT-PCL; (B) EDOT-PCL $\mathrm{L}_{\mathbf{o}}$ and EDOT-PCL in the Chlconcentrated solution; (C) blue film layer appeared after evaporation of the chloroformic solution of EDOT-PCL treated with hydrochloric acid (HCl) (EDOT-PCL exp); (D) FT-IR spectra of EDOT-PCL and EDOT-PCLo.

The AFM investigation allowed us to demonstrate the SA of EDOT-PCL in the two different solvents, as well as to highlight, in the case of ACN, an "order-to-order" type transition in confined spaces (from the dispersion to the thin film), which is mediated by microphase separation and crystallization, thus demonstrating the ability of EDOT-PCL to behave as a "block molecule".

\subsection{EDOT-PCL Behavior in the Presence of Acids}

The phenomena and the experiments described in this section were generated by an unexpected event that occurred during the preparation of the EDOT-PCL concentrated 
solution in $\mathrm{CDCl}_{3}$ for ${ }^{13} \mathrm{C}$-NMR registration. More precisely, a blue color appeared, the intensity of which increased with the increase of the EDOT-PCL amount added.

First, we supposed that the appearance of the specific blue color of PEDOT was a consequence of the self-assembling of EDOT-PCL in $\mathrm{CDCl}_{3}$, which was due to the increase in the solution concentration, thereby forming a supramolecular, linear-like conjugated chain. The phenomenon of a color appearance, when the solution concentration was increased, was also observed by others and was explained in this way [125]. It is important to note that, in the ${ }^{1} \mathrm{H}-\mathrm{NMR}$ spectrum of this blue solution (performed at an EDOT-PCL final concentration of $55 \mathrm{mg} / \mathrm{mL}$ ), there were no obvious changes, as compared to the one recorded at a lower concentration $(6.7 \mathrm{mg} / \mathrm{mL})$ (shown in Figure S1B). This highlights that the appearance of the blue color should be due to other causes. Thus, we went further with the assumption that, in ACN (which is a marginal solvent for PCL), this alleged selfassembling phenomenon could be hindered/affected as PCL has a collapsed conformation, and consequently, regardless of whether it is diluted or concentrated, the ACN solutions should be colorless. As can be seen in Figure 6A, which shows the small bottle and the Erlenmeyer flask on the left side of the image, this supposition was experimentally sustained when solutions, with diluted or concentrated EDOT-PCL in ACN, were prepared.

In order to add supplementary evidence referring to the influence of OCL conformational state (extended or collapsed) on the supramolecular SA, we dissolved a small amount of the dark blue solid, denoted as EDOT-PCL $\mathbf{L}_{\mathbf{o}}$ (which was obtained after the natural evaporation of $\mathrm{CDCl}_{3}$-Figure $\mathrm{S} 8 \mathrm{~A}$ ), in dry acetonitrile. In contrast to the $\mathrm{CDCl}_{3}$ solution, this EDOT-PCL solution is colorless and transparent (see Figure S8B). The only explanation for this difference in solution color could be due to the influence of the collapsed conformation of the OCL side chains on the short conjugated chain of PEDOT that supposedly was formed (vide infra).

In the next step towards understanding the appearance of the EDOT-PCL blue color in $\mathrm{CDCl}_{3}$, we tried to reproduce the facts that were experimentally found during the dissolution of EDOT-PCL to make sure that this phenomenon is reproducible and, eventually, to determine the EDOT-PCL concentration at which the blue color appears.

Thus, using pure grade chloroform from a recently opened bottle, we prepared a new concentrated solution of EDOT-PCL. Surprisingly, the solution remained colorless no matter how much of the macromonomer we dissolved (see the flask on the right side of Figure 6B). Thus, the conclusion was that the appearance of the blue color in the $\mathrm{CDCl}_{3}$ in the NMR registration tube, the intensity of which increased with the added amount of EDOT-PCL, was not related to the formation of a supramolecular polymer by SA but could be due to another reason. Thus, we drew our attention to the well-known fact that deuterated chloroform presents an acidic character during storage for longer than 6 months [126]. The presence of acidic protons $\left(\mathrm{H}^{+}\right)$is relevant because, as it was noted previously, EDOT and a limited number of its derivatives have the mechanistically important capacity to form an active electrophilic intermediate [EDOT-H] ${ }^{+}$. This intermediate is able to initiate oligomerization [127]. If the presence of the acidic protons $\left(\mathrm{H}^{+}\right)$in $\mathrm{CDCl}_{3}$ is accepted, this means that what really happens in the NMR tube could actually be a spontaneous oligomerization reaction of EDOT-PCL in the absence of an oxidant but in acidic media. This is a way for EDOT or EDOT derivatives polymerization that is not so often reported about in the literature $[128,129]$. Starting from this supposition, we added several drops of concentrated hydrochloric acid $(\mathrm{HCl})$ to the colorless, transparent EDOT-PCL solution in $\mathrm{CHCl}_{3}$. The color of the solution remained unchanged for several hours, but we found that a blue pellicle appeared in the vessel the next day, after an overnight reaction, and the solvent evaporated (Figure 6C). This new experimental finding allowed us to conclude that an oligomerization reaction of EDOT-PCL could have taken place in the NMR tube during the attempt to increase the concentration of the solution for ${ }^{13} \mathrm{C}-\mathrm{NMR}$ registration. In order to check for the possibility of oxidant-free, $\mathrm{H}^{+}$-mediated EDOT-PCL oligomerization, FT-IR spectroscopy analysis of the blue solid EDOT-PCL $\mathbf{F}_{\mathbf{o}}$ and UV-vis and fluorescence spectro- 
scopies of EDOT-PCL $\mathbf{F}_{\mathbf{o}}$ in $\mathrm{Chl}$ solution were chosen. The obtained results are presented in Figure 6D, Figure S3A, and Figure 2.

From the IR spectra presented in Figure 6D, the differences between the compared compounds are obvious. The most important difference was registered in the region of $1650-1300 \mathrm{~cm}^{-1}$, which is specific for the characteristic absorptions that originate from the asymmetric and symmetric $\mathrm{C}=\mathrm{C}$ and symmetric $\mathrm{C}-\mathrm{C}$ stretching vibrations of the aromatic thiophene ring [129-132]. Significant modifications also appeared for the peaks that are specific to poly- $\varepsilon$-caprolactone. Generally, a shifting of the peak positions toward wavenumbers with a lower value can be observed. This type of shifting is similar to that which was observed for other thiophene compounds during the transition from monomer to polymer [132]. Thus, in our spectra in Figure 6D, the peaks from $1637 \mathrm{~cm}^{-1}$ and $1584 \mathrm{~cm}^{-1}$ in EDOT-PCL changed the position to 1635 and $1581 \mathrm{~cm}^{-1}$ in EDOT-PCL $\mathbf{L}_{\mathbf{o}}$. Moreover, a new and shallow but discernible absorption peak, centered at approximately $1553 \mathrm{~cm}^{-1}$, appeared in the spectrum of EDOT-PC $\mathbf{L}_{\mathbf{0}}$, which could be attributed to newly formed conjugated sequences. Additionally, the presence in the EDOT-PCL $\mathbf{L}_{\mathbf{o}}$ blue compound of two new small but sharp, individual peaks at $1437 \mathrm{~cm}^{-1}$ and $1327 \mathrm{~cm}^{-1}$, characteristic of PEDOT [130,133], was observed. The most significant shifting from $1192 \mathrm{~cm}^{-1}$ to $1176 \mathrm{~cm}^{-1}$ was that of the band attributed to both PCL and the ethylenedioxy group in EDOT for - $\mathrm{CH} 2$ deformation and $\mathrm{C}-\mathrm{O}-\mathrm{C}$ bending vibration [42]. This shifting could be evidence for a vicinity change of ethylenedioxy-ring in EDOT moiety, caused by the possible appearance of a new short conjugated PEDOT sequence. In Figure S3A and in Figure 2B, the photophysical properties of EDOT-PCL $\mathbf{F}_{\mathbf{o}}$ are presented. The measurements were performed in Chl at the same concentration as for EDOT-PCL. It can be seen that, in comparison to those of the EDOT-PCL, a different absorption for EDOT-PCL $\mathbf{E}_{\mathbf{0}}$ appeared in UV-vis at $345 \mathrm{~nm}$, together with other shallower ones at 380, 425, and $445 \mathrm{~nm}$ (identified in the original spectrum and given in Table S3). For the fluorescence, a noticeable increase in intensity alongside a significant bathochromic shift of the emission maxima (placed in the $400-522 \mathrm{~nm}$ range; see Table S3 for exact values) appeared. These findings more obviously demonstrate that EDOT-PCL evolved into an oligomerized form during dissolution in $\mathrm{CDCl}_{3}$, and this was promoted by the presence of the acidic protons.

This assumption is also supported by the recent claim by Tomsik et al. that protons could have a catalytic effect on the oxidant-free self-polymerization of EDOT and other thiophene derivatives, as they showed that, in the case of EDOT, when the reaction took place in deuterated acetic acid, no self-polymerization occurred [129]. This type of synthesis would be of great interest in terms of finding more sustainable polythiophenes, especially those designed for bioapplications, and this deserves future study.

\section{Conclusions}

In summary, we have presented a $\varepsilon$-caprolactone oligomer that is end-functionalized with an aromatic $\pi$-conjugated EDOT moiety (EDOT-PCL). Synthesized by the ROP of $\varepsilon$-caprolactone, EDOT-PCL was designed as a functional and reactive "hydrophobic amphiphile" and was shown that it could have an interaction-based bias in selective organic solvents. Thus, the non-covalent interactions, which favor self-assembling, are encoded in its structure by the presence of $\pi$-conjugated thiophene ring in the EDOT moiety as well as due to hydroxyl end groups of OCL chains.

The experimental results demonstrate that the self-assembling of EDOT-PCL in the solution and the morphology in thin films are balanced by the mismatch between aromaticaliphatic nature, rigid-flexible character, and between the packing geometry of its structural building elements. Besides these structural peculiarities, the EDOT-PCL SA is determined by the solute-solute, solute-solvent, solute and/or solvent-support interactions assisted by weak non-covalent forces (such as solvophobic-solvophilic character, $\pi-\pi$ interactions, ionic complexation, and hydrogen bonding). Additionally, due to the semicrystalline character of OCL, the bottom-up hierarchical self-assembling of EDOT-PCL is governed by both driving forces, i.e., microphase separation and crystallization. Thus, in both solvents 
and in the thin film obtained from the Chl solution, SA in the nanoscale morphologies was predominantly driven by phase separation, which overwhelms crystallization ordering. It is important to note the metastable nature of the micelle-like nanostructures that are formed in the ACN solution when they were drop-cast in the thin film on mica. Due to solvent evaporation, which triggered the bulky EDOT moiety rearrangement through its particular interaction with the support, the OCL crystals were no longer confined to the nano-/microdomains in which they nucleate, and breakout crystallization occurs. This unexpectedly led to the development of 2D lamellar SCs at room temperature without any supplementary treatment. The AFM investigation revealed, in the case of ACN, an "order-to-order" transition in confined spaces (from dispersion to thin film), mediated by microphase separation and crystallization, thus demonstrating the ability of EDOT-PCL to behave as a "block molecule" in a similar manner as shape amphiphiles, with an essential contribution of the EDOT end-group.

Moreover, the self-assembled supramolecular structures are fluorescent, with increased intensity in less polar chloroform solvent in comparison to ACN. The OCL shell preserved, in this case, the fluorescence of the EDOT moiety. This event is illustrative of the EDOT moiety's impact on the OCL properties, which is dependent on the EDOT placement inside or outside of a confined space into a supramolecular structure. It was shown that EDOT confinement also impacted the crystallization behavior of OCL in a thin film on a support of hydrophilic nature.

Exposing EDOT-PCL in $\mathrm{Chl}$ to inorganic $\mathrm{HCl}$ aqueous solution proposed an answer for the blue color, which unexpectedly appeared during macromonomer dissolution in $\mathrm{CDCl}_{3}$ of acidic nature. EDOT-PCL's oligomerization due to solvent's acidic character could be a preliminary presumptive explanation. In the future, a deep study dedicated to oxidant-free polymerization of EDOT-PCL in the presence of various acids is intended in order to systematically investigate the optimal conditions for synthesis and to fully characterize the eventually obtained PEDOT graft polymer. This method could become a more sustainable pathway for biocompatible PEDOT synthesis.

Supplementary Materials: The following are available online at https:/ /www.mdpi.com/article/ $10.3390 /$ polym $13162720 / \mathrm{s} 1$. Explanatory details; discussion on the ${ }^{1} \mathrm{H}-\mathrm{NMR}$ and ${ }^{13} \mathrm{C}-\mathrm{NMR}$ of EDOT-PCL; calculation of OCL's theoretical diameter of gyration $\mathrm{D}_{\mathrm{G}}$; Table S1: Chemical shifts (ppm) characteristic to ${ }^{1} \mathrm{H}-\mathrm{NMR}$ spectra of EDOT-PCL recorded in $\mathrm{CDCl}_{3}$ and $\mathrm{CD}_{3} \mathrm{CN}$; Table S2: Some physical properties of the used solvents and those related to constitutive parts of EDOTPCL macromonomer; Table S3: Photophysical characteristics of the investigated compounds in solutions; Figure S1. ${ }^{1} \mathrm{H}-\mathrm{NMR}$ spectra of EDOT-PCL macromonomer in (A) $\mathrm{CD}_{3} \mathrm{CN}$ and (B) $\mathrm{CDCl}_{3}$; Figure S2. EDOT-PCL 2D NOESY ${ }^{1} \mathrm{H}^{-1} \mathrm{H}$ experiment registered in $\mathrm{CD}_{3} \mathrm{CN}$ at concentration of $6.66 \mathrm{mg} / \mathrm{mL}$ (whole registered range); Figure S3. (A) UV-vis spectra of EDOT-PCL macromonomer and of its oligomerized form (EDOT-PCL $_{\mathbf{0}}$ ) in indicated solvents at concentration of $1 \mathrm{mg} / \mathrm{mL}$, $\left(0.49 \times 10^{-6} \mathrm{M}\right) ;(\mathbf{B})$ UV-vis spectra of EDOT-PCL macromonomer registered at concentration of $0.5 \mathrm{mg} / \mathrm{mL}\left(0.245 \times 10^{-6} \mathrm{M}\right)$; (C) UV-vis traces of EDOTMeOH in Chl and ACN; (D) fluorescence spectra of EDOTMeOH in Chl $\left(\lambda_{\text {excit }}=262 \mathrm{~nm}\right)$ and ACN $\left(\lambda_{\text {excit }}=254 \mathrm{~nm}\right)$; Figure S4. DLS traces of EDOT-PCL in Chl and in ACN solutions, at the concentration of $1 \mathrm{mg} / \mathrm{mL}$ as (A) intensity-weighted distribution of apparent hydrodynamic diameter $\left(D_{h}\right)$ and as $(\mathbf{B})$ volume-weighted distribution of $D_{h}$; Figure S5. AFM height images of EDOT-PCL films, obtained by drop-casting of its ACN solution on mica, showing round-shaped particles: (A-C) successively magnified areas, marked with the green color, in each image; Figure S6. AFM height images of EDOT-PCL films, obtained by drop-casting of its ACN solution on mica, showing round-shaped particles: (A-C) successively magnified areas, marked with the green color, in each image; Figure S7. AFM height images of EDOT-PCL films, obtained by drop-casting of its $\mathrm{ACN}$ dispersion on mica, used for morphology characterization as detailed in expanded format in Figure 5 (green colour marked areas): (A) a perfect six-sided facetted EDOT-PCL single crystal (SC), expanded in Figure 5E; (B) a non-perfect mono-lamellar EDOT-PCL SC, expanded in Figure 5G; (C) straight and helical rods' breakout crystallization and starting of 2D platelets formation; (D) green arrows showing the rods (most of them in helical shape) placed in the immediate neighborhood of the hexagonally shaped, multilayered EDOT-PCL SCs; Figure S8. (A) Photo showing the bulk form of EDOT-PCL as resulted from the reaction as an 
white-grey powder (middle), of EDOT-PCL as resulted after evaporation of an ACN solution (right) and EDOT-PCL oligomerized form (EDOT-PCL $\mathbf{O}_{\mathbf{o}}$ ), as resulted after evaporation of acidic $\mathrm{CDCl}_{3}$ solution (left); (B) photo showing EDOT-PCL $\mathbf{L}_{\mathbf{o}}$ having dark blue colour in solid state (left) and the colourless, transparent aspect of EDOT-PCL $\mathbf{L}_{\mathbf{0}} \mathrm{ACN}$ solution (which shows a blue colour when is solved in chloroform-see Figure 6B in main manuscript).

Author Contributions: All authors contributed to this study. I.C., experimental conceptualization, synthesis, original draft preparation, funding acquisition, and general supervision; L.C., conceptualization and work design, planning of experiments, AFM data interpretation, all the results integration and interpretation, and manuscript writing; A.-D.B., synthesis, DLS measurements, and all solutions and films preparation, DLS data interpretation and draft preparation for this aspect; G.-L.A., NMR registration and the interpretation of its results; D.G.C., photophysical data analysis and interpretation, draft preparation for this aspect, discussion assistance, and revision of the manuscript; E.-L.U., AFM measurements. I.C., A.-D.B. and G.-L.A.-drew the figures. All authors corrected the draft and agreed to its submission. All authors have read and agreed to the published version of the manuscript.

Funding: This work was jointly supported by Romanian Academy and by the Ministry of Research and Innovation, CNCS-UEFISCDI, project number PN-III-P4-ID-PCCF-2016-0050, within PNCDI III.

Institutional Review Board Statement: Not applicable.

Informed Consent Statement: Not applicable.

Data Availability Statement: Tha data presented in this study are available on request from the corresponding authors.

Acknowledgments: The authors A.-D.B., L.C., G.-L.A., E.-L.U. and I.C. gratefully acknowledge the financial support from the Ministry of Research and Innovation CNCS-UEFISCDI given by Project number PN-III-P4-ID-PCCF-2016-0050, Acronym 5D-nanoP.

Conflicts of Interest: The authors declare no conflict of interest.

\section{References}

1. Polymeropoulos, G.; Zapsas, G.; Ntetsikas, K.; Bilalis, P.; Gnanou, Y.; Hadjichristidis, N. 50th Anniversary Perspective: Polymers with Complex Architectures. Macromolecules 2017, 50, 1253-1290. [CrossRef]

2. Lorenzo, A.T.; Muller, A.J.; Lin, M.-C.; Chen, H.-L.; Jeng, U.-S.; Priftis, D.; Pitsikalis, M.; Hadjichristidis, N. Influence of Macromolecular Architecture on the Crystallization of (PCL2)-b-(PS2) 4-Miktoarm Star Block Copolymers in Comparison to Linear PCL-b-PS Diblock Copolymer Analogues. Macromolecules 2009, 42, 8353-8364. [CrossRef]

3. Hadjichristidis, N.; Pispas, S.; Pitsikalis, M. End-functionalized polymers with zwitterionic end-groups. Prog. Polym. Sci. 1999, 24, 875-915. [CrossRef]

4. Lunn, D.J.; Discekici, E.H.; Read de Alaniz, J.; Gutekunst, W.R.; Hawker, C.J. Established and Emerging Strategies for Polymer Chain-End Modification. J. Polym. Sci. Part A Polym. Chem. 2017, 55, 2903-2914. [CrossRef]

5. Liang, Y.; Deng, X.; Zhang, L.; Peng, X.; Gao, W.; Cao, J.; Gu, Z.; He, B. Terminal modification of polymeric micelles with $\pi$-conjugated moieties for efficient anticancer drug delivery. Biomaterials 2015, 71, 1-10. [CrossRef] [PubMed]

6. Rosberg, J.; Rottke, F.O.; Schulz, B.; Lendlein, A. Enzymatic Degradation of Oligo(e-caprolactone)s End-Capped with Phenylboronic Acid Derivatives at the Air-Water Interface. Macromol. Rapid Commun. 2016, 37, 1966-1971. [CrossRef] [PubMed]

7. Jiang, Y.; Hadjichristidis, N. Tetraphenylethene-Functionalized Polyethylene-Based Polymers with Aggregation-Induced Emission. Macromolecules 2019, 52, 1955-1964. [CrossRef]

8. Kim, J.; Jung, H.Y.; Park, M.J. End-Group Chemistry and Junction Chemistry in Polymer Science: Past, Present, and Future. Macromolecules 2020, 53, 746-763. [CrossRef]

9. Cianga, I.; Yagci, Y. New polyphenylene-based macromolecular architectures by using well defined macromonomers synthesized via controlled polymerization methods. Prog. Polym. Sci. 2004, 29, 387-399. [CrossRef]

10. Priya, M.H.; Pratt, L.R.; Paulaitis, M.E. Effect of PEG End-Group Hydrophobicity on Lysozyme Interactions in Solution Characterized by Light Scattering. Langmuir 2011, 27, 13713-13718. [CrossRef]

11. Cheng, Y.; Hao, J.; Lee, L.A.; Biewer, M.C.; Wang, Q.; Stefan, M.C. Thermally Controlled Release of Anticancer Drug from Self-Assembled $\gamma$-Substituted Amphiphilic Poly( $\varepsilon$ caprolactone) Micellar Nanoparticles. Biomacromolecules 2012, 13, $2163-2173$. [CrossRef]

12. Bendrea, A.-D.; Fabregat, G.; Cianga, L.; Estrany, F.; del Valle, L.J.; Cianga, I.; Aleman, C. Hybrid materials consisting of an all-conjugated polythiophene backbone and grafted hydrophilic poly(ethylene glycol) chains. Polym. Chem. 2013, 4, $2709-2723$. [CrossRef] 
13. Dominguez-Alfaro, A.; Gabirondo, E.; Alegret, N.; De León-Almazán, C.M.; Hernandez, R.; Vallejo-Illarramendi, A.; Prato, M.; Mecerreyes, D. 3D Printable Conducting and Biocompatible PEDOT-graft-PLA Copolymers by Direct Ink Writing. Macromol. Rapid Commun. 2021, 2100100. [CrossRef]

14. Cianga, I.; Mercore, V.M.; Grigoras, M.; Yagci, Y. Poly(thienyl-phenylene)s with Macromolecular Side Chains by Oxidative Polymerization of Well-Defined Macromonomers. J. Polym. Sci. Part A Polym. Chem. 2007, 45, 848-865. [CrossRef]

15. Marina, S.; Mantione, D.; Manoj Kumar, K.; Kari, V.; Gutierrez, J.; Tercjak, A.; Sanchez-Sanchez, A.; Mecerreyes, D. New electroactive macromonomers and multi-responsive PEDOT graft copolymers. Polym. Chem. 2018, 9, 3780-3790. [CrossRef]

16. Colak, D.G.; Cianga, I.; Muftoglu, A.E.; Yagci, Y. Synthesis and Characterization of Mid- and End-Chain Functional Telechelics by Controlled Polymerization Methods and Coupling Processes. J. Polym. Sci. Part A Polym. Chem. 2006, 44, 727-743. [CrossRef]

17. Papila, O.; Toppare, L.; Yagci, Y.; Cianga, L. Conducting Copolymers of Thiophene- Functionalized Polystyrene. Int. J. Polym. Anal. Charact. 2004, 9, 13-28. [CrossRef]

18. Scheinhardt, B.; Trzaskowski, J.; Baier, M.C.; Stempfle, B.; Oppermann, A.; Woll, D.; Mecking, S. Anisotropic Polyethylene Nanocrystals Labeled with a Single Fluorescent Dye Molecule: Toward Monitoring of Nanoparticle Orientation. Macromolecules 2013, 46, 7902-7910. [CrossRef]

19. Demir, B.; Yilmaz, T.; Guler, E.; Pinar Gumus, Z.; Akbulut, H.; Aldemir, E.; Coskunol, H.; Colak, D.G.; Cianga, I.; Yamada, S.; et al. Polypeptide with electroactive endgroups as sensing platform for the abused drug 'methamphetamine' by bioelectrochemical method. Talanta 2016, 161, 789-796. [CrossRef]

20. Li, C.Y. The rise of semicrystalline polymers and why are they still interesting. Polymer 2020, 211, 123150. [CrossRef]

21. Sisson, A.L.; Ekinci, D.; Lendlein, A. The contemporary role of $\varepsilon$-caprolactone chemistry to create advanced polymer architectures. Polymer 2013, 54, 4333-4350. [CrossRef]

22. Diaconescu, R.; Simionescu, B.C.; David, G. Control and prediction of degradation of biopolymer based hydrogels with poly( $\varepsilon$-caprolactone) subunits. Int. J. Biol. Macromol. 2014, 71, 147-154. [CrossRef]

23. Simionescu, B.C.; Drobota, M.; Timpu, D.; Vasiliu, T.; Constantinescu, C.A.; Rebleanu, D.; Calin, M.; David, G. Biopolymers / poly( $\varepsilon-$ caprolactone)/polyethylenimine functionalized nanohydroxyapatite hybrid cryogel: Synthesis, characterization and application in gene delivery. Mater. Sci. Eng. C 2017, 81, 167-176. [CrossRef] [PubMed]

24. David, G.; Turin-Moleavin, I.; Ursu, L.-E.; Peptanariu, D.; Ailincai, D. Multilayer biopolymer/poly( $\varepsilon$-caprolactone)/polycation nanoparticles. Iran. Polym. J. 2018, 27, 517-526. [CrossRef]

25. Ganda, S.; Dulle, M.; Drechsler, M.; Forster, B.; Forster, S.; Stenzel, M.H. Two-Dimensional Self-Assembled Structures of Highly Ordered Bioactive Crystalline-Based Block Copolymers. Macromolecules 2017, 50, 8544-8553. [CrossRef]

26. Al-Sulami, A.; Ladelta, V.; Hadjichristidis, N. In-chain functionalized poly( $\varepsilon$-caprolactone): A valuable precursor towards the synthesis of 3-miktoarm star containing hyperbranched polyethylene. J. Polym. Sci. 2020, 58, 2764-2773. [CrossRef]

27. Uyar, T.; Cianga, I.; Cianga, L.; Besenbacher, F.; Yagci, Y. Self-aligned and bundled electrospun fibers prepared from blends of polystyrene (PS) and poly(methyl methacrylate) (PMMA) with a hairy-rod polyphenylene copolymer. Mater. Lett. 2009, 63, 1638-1641. [CrossRef]

28. Hardy, J.G.; Villancio-Wolter, M.K.; Sukhavasi, R.C.; Mouser, D.J.; Aguilar, D., Jr.; Geissler, S.A.; Kaplan, D.L.; Schmidt, C.E. Electrical Stimulation of Human Mesenchymal Stem Cells on Conductive Nanofibers Enhances their Differentiation toward Osteogenic Outcomes. Macromol. Rapid Commun. 2015, 36, 1884-1890. [CrossRef] [PubMed]

29. Mei, S.; Staub, M.; Li, C.Y. Directed Nanoparticle Assembly through Polymer Crystallization. Chem. Eur. J. 2020, $26,349-361$. [CrossRef]

30. Odrobinska, J.; Neugebauer, D. Micellar Carriers Based on Amphiphilic PEG/PCL Graft Copolymers for Delivery of Active Substances. Polymers 2020, 12, 2876. [CrossRef]

31. Uyar, Z.; Durgun, M.; Sukru Yavuz, M.; Bahattin Abaci, M.; Arslan, U.; Degirmenci, M. Two-arm PCL and PLLA macrophotoinitiators with benzoin end-functional groups by combination of ROP and click chemistry and their use in the synthesis of A2B2 type miktoarm star copolymers. Polymer 2017, 123, 153-168. [CrossRef]

32. Uyar, Z.; Cay, N.G.B.; Arslan, U.; Durgun, M.; Degirmenci, M. Synthesis and characterization of an A2B2-type miktoarm star copolymer based on poly(e-caprolactone) and poly(cyclohexene oxide). Polym. Bull. 2019, 76, 553-573. [CrossRef]

33. Degirmenci, M.; Izgin, O.; Yagci, Y. Synthesis and Characterization of Cyclohexene Oxide Functional Poly( $\varepsilon$-caprolactone) Macromonomers and Their Use in Photoinitiated Cationic Homo- and Copolymerization. J. Polym. Sci. Part A Polym. Chem. 2004, 42, 3365-3372. [CrossRef]

34. Kang, E.-H.; Lee, I.-H.; Choi, T.-L. Brush Polymers Containing Semiconducting Polyene Backbones: Graft-Through Synthesis via Cyclopolymerization and Conformational Analysis on the Coil-to-Rod Transition. ACS Macro Lett. 2012, 1, 1098-1102. [CrossRef]

35. Nikovia, C.; Sougioltzoupoulou, E.; Rigas, V.; Pitsikalis, M. Macromolecular Brushes Based on Poly(L-Lactide) and Poly( $\varepsilon-$ Caprolactone) Single and Double Macromonomers via ROMP. Synthesis, Characterization and Thermal Properties. Polymers 2019, 11, 1606. [CrossRef]

36. Hadjichristidis, N.; Pitsikalis, M.; Iatrou, H.; Pispas, S. The Strength of the Macromonomer Strategy for Complex Macromolecular Architecture: Molecular Characterization, Properties and Applications of Polymacromonomers. Macromol. Rapid Commun. 2003, 24, 979-1013. [CrossRef]

37. Müllner, M.; Müller, A.H.E. Cylindrical polymer brushes-Anisotropic building blocks, unimolecular templates and particulate nanocarriers. Polymer 2016, 98, 389-401. [CrossRef] 
38. Xie, G.; Martinez, M.R.; Olszewski, M.; Sheiko, S.S.; Matyjaszewski, K. Molecular Bottlebrushes as Novel Materials. Biomacromolecules 2019, 20, 27-54. [CrossRef]

39. Knaapila, M.; Stepanyan, R.; Lyons, B.P.; Torkkeli, M.; Monkman, A.P. Towards General Guidelines for Aligned, Nanoscale Assemblies of Hairy-Rod Polyfluorene. Adv. Funct. Mater. 2006, 16, 599-609. [CrossRef]

40. Mecerreyes, D.; Pomposo, J.A.; Bengoetxea, M.; Grande, H. Novel Pyrrole End-Functional Macromonomers Prepared by Ring-Opening and Atom-Transfer Radical Polymerizations. Macromolecules 2000, 33, 5846-5849. [CrossRef]

41. Molina, B.G.; Bendrea, A.D.; Cianga, L.; Armelin, E.; del Valle, L.J.; Cianga, I.; Alemán, C. The biocompatible polythiophene-gpolycaprolactone copolymer as an efficient dopamine sensor platform. Polym. Chem. 2017, 8, 6112-6122. [CrossRef]

42. Molina, B.G.; Bendrea, A.-D.; Lanzalaco, S.; Franco, L.; Cianga, L.; del Valle, L.J.; Puiggali, J.; Turon, P.; Armelin, E.; Cianga, I.; et al. Smart design for a flexible, functionalized an electroresponsive hybrid platform based on poly(3,4-ethylenedioxythiophene) derivatives to improve cell viability. J. Mater. Chem. B 2020, 8, 8864-8877. [CrossRef]

43. Molina, B.G.; Cianga, L.; Bendrea, A.-D.; Cianga, I.; Aleman, C.; Armelin, E. An amphiphilic, heterografted polythiophene copolymer containing biocompatible/ biodegradable side chains for use as an (electro) active surface in biomedical applications. Polym. Chem. 2019, 10, 5010-5022. [CrossRef]

44. Chang, S.H.; Lee, H.J.; Park, S.; Kim, Y.; Jeong, B. Fast Degradable Polycaprolactone for Drug Delivery. Biomacromolecules 2018, 19, 2302-2307. [CrossRef] [PubMed]

45. Tang, X.; Saveh-Shemshaki, N.; Kan, H.-M.; Khan, Y.; Laurencin, C.T. Biomimetic Electroconductive Nanofibrous Matrices for Skeletal Muscle Regenerative Engineering. Regen. Eng. Transl. Med. 2020, 6, 228-237. [CrossRef] [PubMed]

46. Ritzau-Reid, K.I.; Spicer, C.D.; Gelmi, A.; Grigsby, C.L.; Ponder, J.F., Jr.; Bemmer, V.; Creamer, A.; Vilar, R.; Serio, A.; Stevens, M.M. An Electroactive Oligo-EDOT Platform for Neural Tissue Engineering. Adv. Funct. Mater. 2020, 30, 2003710. [CrossRef] [PubMed]

47. Hollamby, M.J.; Karny, M.; Bomans, P.H.H.; Sommerdijk, N.A.J.M.; Saeki, A.; Seki, S.; Minamikawa, H.; Grillo, I.; Pauw, B.R.; Brown, P.; et al. Directed assembly of optoelectronically active alkyl- $\pi$-conjugated molecules by adding $n$-alkanes or $\pi$-conjugated species. Nat. Chem. 2014, 6, 690-696. [CrossRef]

48. Zha, R.H.; de Waal, B.F.M.; Lutz, M.; Teunissen, A.J.P.; Meijer, E.W. End Groups of Functionalized Siloxane Oligomers Direct Block-Copolymeric or Liquid-Crystalline Self-Assembly Behavior. J. Am. Chem. Soc. 2016, 138, 5693-5698. [CrossRef] [PubMed]

49. Li, X.; Xu, W.; Chang, X.; Zheng, Y.; Ni, L.; Shan, G.; Bao, Y.; Pan, P. Stepwise Crystallization and Induced Microphase Separation in Nucleobase Monofunctionalized Supramolecular Poly( $\varepsilon$-caprolactone). Macromolecules 2021, 54, 846-857. [CrossRef]

50. Polarz, S.; Kunkel, M.; Donner, A.; Schlotter, M. Added-Value Surfactants. Chem. Eur. J. 2018, 24, 18842-18856. [CrossRef]

51. Simionescu, C.I.; Grovu-Ivanoiu, M.; Cianga, I.; Grigoras, M.; Duca, A.; Cocarla, I. Electrochemical polymerization of some monomers with Schiff's base structure. Angew. Makromol. Chem. 1996, 239, 1-12. [CrossRef]

52. Pietrasik, J.; Sumerlin, B.S.; Lee, H.-I.; Gil, R.R.; Matyjaszewski, K. Structural mobility of molecular bottle-brushes investigated by NMR relaxation dynamics. Polymer 2007, 48, 496-501. [CrossRef]

53. Cianga, L.; Sarac, A.; Ito, K.; Yagci, Y. Synthesis and Characterization of New Alternating, Amphiphilic, Comblike Copolymers of Poly(ethylene oxide) Macromonomer and N-Phenylmaleimide. J. Polym. Sci. Part A Polym. Chem. 2005, 43, 479-492. [CrossRef]

54. Dissanayake, D.S.; Sheina, E.; Biewer, M.C.; McCullough, R.D.; Stefan, M.C. Determination of Absolute Molecular Weight of Regioregular Poly(3-Hexylthiophene) by ${ }^{1} \mathrm{H}-\mathrm{NMR}$ Analysis. J. Polym. Sci. Part A Polym. Chem. 2017, 55, 79-82. [CrossRef]

55. Cianga, L.; Bendrea, A.-D.; Fifere, N.; Nita, L.E.; Doroftei, F.; Ag, D.; Seleci, M.; Timur, S.; Cianga, I. Fluorescent micellar nanoparticles by selfassembly of amphiphilic, nonionic and water selfdispersible polythiophenes with "hairy rod" architecture. RSC Adv. 2014, 4, 56385-56405. [CrossRef]

56. Boccia, A.C.; Lukes, V.; Eckstein-Andicsova, A.; Kozma, E. Solvent- and concentration-induced self-assembly of an amphiphilic perylene dye. New J. Chem. 2020, 44, 892-899. [CrossRef]

57. Abraham, R.J.; Mobli, M.; Smith, R.J. ${ }^{1} \mathrm{H}$ chemical shifts in NMR: Part 19. Carbonyl anisotropies and steric effects in aromatic aldehydes and ketones. Magn. Reson. Chem. 2003, 41, 26-36. [CrossRef]

58. Lomas, J.S. ${ }^{1} \mathrm{H}$ NMR spectra of alcohols in hydrogen bonding solvents: DFT/GIAO calculations of chemical shifts. Magn. Reson. Chem. 2016, 54, 28-38. [CrossRef]

59. Kontogianni, V.G.; Charisiadis, P.; Primikyri, A.; Pappas, C.G.; Exarchou, V.; Tzakos, A.G.; Gerothanassis, I.P. Hydrogen bonding probes of phenol-OH groups. Org. Biomol. Chem. 2013, 11, 1013-1025. [CrossRef]

60. Zhou, Y.; Zheng, Y.-Z.; Sun, H.-Y.; Deng, G.; Yu, Z.-W. Hydrogen bonding interactions in ethanol and acetonitrile binary system: A near and mid-infrared spectroscopic study. J. Mol. Struct. 2014, 1069, 251-257. [CrossRef]

61. Luo, C.J.; Stride, E.; Edirisinghe, M. Mapping the Influence of Solubility and Dielectric Constant on Electrospinning Polycaprolactone Solutions. Macromolecules 2012, 45, 4669-4680. [CrossRef]

62. Boucher, D.S. Solubility parameters and solvent affinities for polycaprolactone: A comparison of methods. J. Appl. Polym. Sci. 2020, 137, 48908. [CrossRef]

63. Liang, Y.; Sun, Y.; Fu, X.; Lin, Y.; Meng, Z.; Meng, Y.; Niu, J.; Lai, Y.; Sun, Y. The effect of $\pi$-Conjugation on the self-assembly of micelles and controlled cargo release. Artif. Cells Nanomed. Biotechnol. 2020, 48, 525-532. [CrossRef] [PubMed]

64. Mo, H.; Pochapsky, T.C. Intermolecular interactions characterized by nuclear Overhauser effects. Prog. Nucl. Magn. Reson. Spectrosc. 1997, 30, 1-38. [CrossRef]

65. Voets, I.K.; De Keizer, A.; Cohen Stuart, M.A. Core and Corona Structure of Mixed Polymeric Micelles. Macromolecules 2006, 39, 5952-5955. [CrossRef] 
66. Landry, J.M.; Marangoni, D.G.; Lumsdern, M.D.; Berno, R. 1D and 2D NMR investigations of micelle-formation process in 8-phenyloctanoate micelles. Can. J. Chem. 2007, 85, 202-207. [CrossRef]

67. Elgiddawy, N.; Ren, S.; Yassar, A.; Louis-Joseph, A.; Sauriat-Dorizon, H.; El Rouby, W.M.A.; El-Gendy, A.O.; Farghali, A.A.; Korri-Youssoufi, H. Dispersible Conjugated Polymer Nanoparticles as Biointerface Materials for Label-Free Bacteria Detection. ACS Appl. Mater. Interfaces 2020, 12, 39979-39990. [CrossRef]

68. Hostnik, G.; Podlipnik, C.; Meriguet, G.; Cerar, J. Specificity of Counterion Binding to a Conjugated Polyelectrolyte: A Combined Molecular Dynamics and NOESY Investigation. Macromolecules 2020, 53, 1119-1128. [CrossRef]

69. Hasan, N.; Fuchs, C.; Schwieger, C.; Busse, K.; Dolynchuk, O.; Kressler, J. Crystallization of poly( $\varepsilon$-caprolactone) at the air-water interface studied by IRRAS and GI-WAXS. Polymer 2020, 196, 122468. [CrossRef]

70. Song, I.Y.; Kim, J.; Im, M.J.; Moon, B.J.; Park, T. Synthesis and Self-Assembly of Thiophene-Based All-Conjugated Amphiphilic Diblock Copolymers with a Narrow Molecular Weight Distribution. Macromolecules 2012, 45, 5058-5068. [CrossRef]

71. Colak, D.G.; Cianga, I.; Cianga, L.; Yagci, Y. Synthesis and self-assembly of fluorenevinylene alternating copolymers in "HairyRod" architecture: Side chain-mediated tuning of conformation, microstructure and photophysical properties. Des. Monomers Polym. 2016, 19, 508-534. [CrossRef]

72. Bendrea, A.-D.; Cianga, L.; Hitruc, E.G.; Titorencu, I.; Cianga, I. Fluorescent Nanoparticles from "Hairy-Rods", Water-Self Dispersible Amphiphilic Polythiophenes. Mater. Plast. 2013, 50, 71-78.

73. Bendrea, A.-D.; Cianga, L.; Hitruc, E.G.; Cianga, I. Synthesis and Characterization of Fluorescent, Nonionic, Water Self-Dispersible Oligothiophenes. Int. J. Polym. Anal. Charact. 2013, 18, 189-198. [CrossRef]

74. Casado, N.; Hernandez, G.; Veloso, A.; Devaraj, S.; Mecerreyes, D.; Armand, M. PEDOT Radical Polymer with Synergetic Redox and Electrical Properties. ACS Macro Lett. 2016, 5, 59-64. [CrossRef] [PubMed]

75. Ghosh, S.; Remita, H.; Ramos, L.; Dazzi, A.; Deniset-Besseau, A.; Beaunier, P.; Goubard, F.; Aubert, P.-H.; Brisset, F.; Remita, S. PEDOT nanostructures synthesized in hexagonal mesophases. New J. Chem. 2014, 38, 1106-1115. [CrossRef]

76. Zambianchi, M.; Di Maria, F.; Cazzato, A.; Gigli, G.; Piacenza, M.; Della Sala, F.; Barbarella, G. Microwave-Assisted Synthesis of Thiophene Fluorophores, Labeling and Multilabeling of Monoclonal Antibodies, and Long Lasting Staining of Fixed Cells. J. Am. Chem. Soc. 2009, 131, 10892-10900. [CrossRef] [PubMed]

77. Clark, A.P.-Z.; Shi, C.; Ng, B.C.; Wilking, J.N.; Ayzner, A.L.; Stieg, A.Z.; Schwartz, B.J.; Mason, T.G.; Rubin, Y.; Tolbert, S.H. Self-Assembling Semiconducting Polymers- Rods and Gels from Electronic Materials. ACS Nano 2013, 7, 962-977. [CrossRef]

78. Poater, J.; Casanovas, J.; Sola, M.; Aleman, C. Examining the Planarity of Poly(3,4-ethylenedioxythiophene): Consideration of Self-Rigidification, Electronic, and Geometric Effects. J. Phys. Chem. A 2010, 114, 1023-1028. [CrossRef]

79. Conboy, G.; Spencer, H.J.; Angioni, E.; Kanibolotsky, A.L.; Findlay, N.J.; Coles, S.J.; Wilson, C.; Pitak, M.B.; Risko, C.; Coropceanu, V.; et al. To bend or not to bend-are heteroatom interactions within conjugated molecules effective in dictating conformation and planarity? Mater. Horiz. 2016, 3, 333-339. [CrossRef]

80. Bendrea, A.-D.; Cianga, L.; Cianga, I. Poly(ethylene glycol)- functionalized Water Self-Dispersible $\alpha$-Terthiophenes. Rev. Roum. Chim. 2013, 58, 153-160.

81. Rayeroux, D.; Travelet, C.; Lapinte, V.; Borsali, R.; Robin, J.-J.; Bouilhac, C. Tunable amphiphilic graft copolymers bearing fatty chains and polyoxazoline: Synthesis and self-assembly behavior in solution. Polym. Chem. 2017, 8, 4246-4263. [CrossRef]

82. Xiang, L.; Ryu, W.; Kim, H.; Ree, M. Precise Synthesis, Properties, and Structures of Cyclic Poly(E-caprolactone)s. Polymers 2018, 10, 577. [CrossRef]

83. Rodrigues-Ropero, F.; Casanovas, J.; Aleman, C. Ab Initio Calculations on $\pi$-Stacked Thiophene Dimer, Trimer, and Tetramer: Structure, Interaction Energy, Cooperative Effects, and Intermolecular Electronic Parameters. J. Comput. Chem. 2008, $29,69-78$. [CrossRef]

84. Guo, C.; Huo, G. Poor solvent as a nucleating agent to induce poly( $\varepsilon$-caprolactone) ultrathin film crystallization on poly(vinylpyrrolidone) substrate. Colloid Polym. Sci. 2016, 294, 767-776. [CrossRef]

85. Zhao, J.; Zhang, J.; Duan, X.; Peng, Z.; Wang, S. Formation mechanism, chain folding, and growth behavior of the intriguing fiber-like crystal of poly (ethylene oxide-b-e-caprolactone) block copolymer in ultra thin films. Polymer 2011, 52, $2085-2093$. [CrossRef]

86. Huang, Y.; Liu, X.-B.; Zhang, H.-L.; Zhu, D.-S.; Sun, Y.-J.; Yan, S.-K.; Wang, J.; Chen, X.-F.; Wan, X.-H.; Chen, E.-Q.; et al. AFM study of crystallization and melting of a poly(ethylene oxide) diblock copolymer containing a tablet-like block of poly\{2,5-bis[(4methoxyphenyl)oxycarbonyl]styrene\} in ultra thin films. Polymer 2006, 47, 1217-1225. [CrossRef]

87. Wang, J.; Li, L.; Yang, W.; Yan, Z.; Zhou, Y.; Wang, B.; Zhang, B.; Bu, W. Sub-10 nm Scale Lamellar Structures with a High Degree of Long-Range Order Fabricated by Orthogonal Self-Assembly of Crown Ether/Secondary Dialkylammonium Recognition and Metal $\cdots$ Metal/ $\pi-\pi$ Interactions. ACS Macro Lett. 2019, 8, 1012-1016. [CrossRef]

88. Levent Demirel, A.; Yurteri, S.; Cianga, I.; Yagci, Y. Layered Morphology of Poly(phenylene)s in Thin Films Induced by Substitution of Well-Defined Poly(E-caprolactone) Side Chains. Macromolecules 2005, 38, 6402-6410. [CrossRef]

89. He, W.-N.; Xu, J.-T. Crystallization assisted self-assembly of semicrystalline block copolymers. Prog. Polym. Sci. 2012, 37, 1350-1400. [CrossRef]

90. Crassous, J.J.; Schurtenberger, P.; Ballauff, M.; Mihut, A.M. Design of block copolymer micelles via crystallization. Polymer 2015, 62, A1-A13. [CrossRef] 
91. Van Horn, R.M.; Steffen, M.R.; O’Connor, D. Recent progress in block copolymer crystallization. Polym. Crystall. 2018,1 , e10039. [CrossRef]

92. Michell, R.M.; Müller, A.J. Confined crystallization of polymeric materials. Prog. Polym. Sci. 2016, 54-55, 183-213. [CrossRef]

93. Liu, Y.-X.; Chen, E.-Q. Polymer crystallization of ultrathin films on solid substrates. Coord. Chem. Rev. 2010, 254, 1011-1037. [CrossRef]

94. Ganda, S.; Stenzel, M.H. Concepts, fabrication methods and applications of living crystallization-driven self-assembly of block copolymers. Prog. Polym. Sci. 2020, 101, 101195. [CrossRef]

95. Cha, Y.; Jarrett-Wilkins, C.; Rahman, M.A.; Zhu, T.; Sha, Y.; Manners, I.; Tang, C. Crystallization-Driven Self-Assembly of Metallo-Polyelectrolyte Block Copolymers with a Polycaprolactone Core-Forming Segment. ACS Macro Lett. 2019, 8, 835-840. [CrossRef]

96. Rejek, T.; Schweizer, P.; Joch, D.; Portilla, L.; Spiecker, E.; Halik, M. Buried Microphase Separation by Dynamic Interplay of Crystallization and Microphase Separation in Semicrystalline PEO Rich PS-b-PEO Block Copolymer Thin Films. Macromolecules 2020, 53, 5604-5613. [CrossRef]

97. Wei, Y.; Pan, C.; Li, B.; Han, Y. Self-assembly morphology effects on the crystallization of semicrystalline block copolymer thin film. J. Chem. Phys. 2007, 126, 104902. [CrossRef]

98. Di Maria, F.; Fabiano, E.; Gentili, D.; Biasiucci, M.; Salzillo, T.; Bergamini, G.; Gazzano, M.; Zanelli, A.; Brillante, A.; Cavallini, M.; et al. Polymorphism in Crystalline Microfibers of Achiral Octithiophene: The Effect on Charge Transport, Supramolecular Chirality and Optical Properties. Adv. Funct. Mater. 2014, 24, 4943-4951. [CrossRef]

99. Vleugels, M.E.J.; de Zwart, M.E.; Magana, J.R.; Lamers, B.A.G.; Voets, I.K.; Meijer, E.W.; Petkau-Milroy, K.; Palmans, A.R.A. Effects of crystallinity and dispersity on the self-assembly behavior of block co-oligomers in water. Polym. Chem. 2020, 11, 7170-7177. [CrossRef]

100. Doncom, K.E.B.; Blackman, L.D.; Wright, D.B.; Gibson, M.I.; O’Reilly, R.K. Dispersity effects in polymer self-assemblies: A matter of hierarchical control. Chem. Soc. Rev. 2017, 46, 4119-4134. [CrossRef]

101. Wang, G.; Jiang, C.; Gao, C.; Wang, X.; Chen, G. Dispersion of Electrically Conductive Polymer PEDOT in Organic Solvents. Acta Polym. Sin. 2014, 11, 1532-1538. [CrossRef]

102. Kawazu, K.; Nakagawa, S.; Ishizone, T.; Nojima, S. Effects of Bulky End-Groups on the Crystallization Kinetics of Poly( $\varepsilon$ caprolactone) Homopolymers Confined in a Cylindrical Nanodomain. Macromolecules 2017, 50, 7202-7210. [CrossRef]

103. Zhang, L.; Wang, T.; Shen, Z.; Liu, M. Chiral Nanoarchitectonics: Towards the Design, Self-Assembly, and Function of Nanoscale Chiral Twists and Helices. Adv. Mater. 2016, 28, 1044-1059. [CrossRef]

104. Song, B.; Liu, B.; Jin, Y.; He, X.; Tang, D.; Wu, G.; Yin, S. Controlled self-assembly of helical nano-ribbons formed by achiral amphiphiles. Nanoscale 2015, 7, 930-935. [CrossRef]

105. Lee, E.; Hammer, B.; Kim, J.-K.; Page, Z.; Emrick, T.; Hayward, R.C. Hierarchical Helical Assembly of Conjugated Poly(3hexylthiophene)-block-poly(3-triethylene glycol thiophene) Diblock Copolymers. J. Am. Chem. Soc. 2011, 133, 10390-10393. [CrossRef] [PubMed]

106. Cui, Y.; Tao, D.; Huang, X.; Lu, G.; Feng, C. Self-Assembled Helical and Twisted Nanostructures of a Preferred Handedness from Achiral $\pi$-Conjugated Oligo(p-phenylenevinylene) Derivatives. Langmuir 2019, 35, 3134-3142. [CrossRef] [PubMed]

107. Zhong, S.; Cui, H.; Chen, Z.; Wooley, K.L.; Pochan, D.J. Helix self-assembly through the coiling of cylindrical micelles. Soft Matter 2008, 4, 90-93. [CrossRef]

108. Sanandaji, N.; Ovaskainen, L.; Gunnewiek, M.K.; Vancso, G.J.; Hedenqvist, M.S.; Yu, S.; Eriksson, L.; Roth, S.V.; Gedde, U.W. Unusual crystals of poly( $\varepsilon$-caprolactone) by unusual crystallisation: The effects of rapid cooling and fast solvent loss on the morphology, crystal structure and melting. Polymer 2013, 54, 1497-1503. [CrossRef]

109. Iwata, T.; Furuhashi, Y.; Su, F.; Doi, Y. Single crystal morphologies of biodegradable aliphatic polyesters. Riken Rev. 2001, 42, $15-18$.

110. Iwata, T.; Doi, Y. Morphology and enzymatic degradation of poly( $\varepsilon$-caprolactone) single crystals: Does a polymer single crystal consist of micro-crystals? Polym. Int. 2002, 51, 852-858. [CrossRef]

111. Zhang, H.; Liu, M.; Zhou, T.; Dong, B.; Li, C.Y. Stepwise assembly of a cross-linked free-standing nanoparticle sheet with controllable shape. Nanoscale 2015, 7, 11033-11039. [CrossRef] [PubMed]

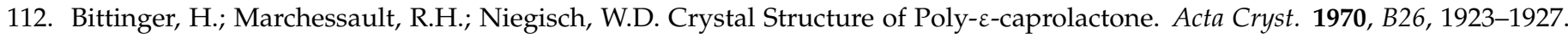
[CrossRef]

113. Su, M.; Huang, H.; Ma, X.; Wang, Q.; Su, Z. Poly(2-vinylpyridine)-block-Poly(E-caprolactone) Single Crystals in Micellar Solution. Macromol. Rapid Commun. 2013, 34, 1067-1071. [CrossRef] [PubMed]

114. Mareau, V.H.; Prud'Homme, R.E. In-Situ Hot Stage Atomic Force Microscopy Study of Poly( $\varepsilon$-caprolactone) Crystal Growth in Ultrathin Films. Macromolecules 2005, 38, 398-408. [CrossRef]

115. Beekmans, L.G.M.; Vancso, G.J. Real-time crystallization study of poly(e-caprolactone) by hot-stage atomic force microscopy. Polymer 2000, 41, 8975-8981. [CrossRef]

116. Qi, H.; Wang, W.; Li, C.Y. Janus Polymer Single Crystal Nanosheet via Evaporative Crystallization. ACS Macro Lett. 2014, 3 , 675-678. [CrossRef]

117. Nunez, E.; Gedde, U.W. Single crystal morphology of star-branched polyesters with crystallisable poly(3-caprolactone) arms. Polymer 2005, 46, 5992-6000. [CrossRef] 
118. Lotz, B.; Wittmann, J.C. Structure of Polymer Single Crystals in Materials Science and Technology, Structure and Properties of Polymers; Cahn, R.W., Haasen, P., Kramer, E.J., Eds.; VCH: Weinheim, Germany, 1993; Volume 12, pp. 79-151, Chapter 3.

119. Diaz, A.; Bacaicoa, A.; Casas, M.T.; Franco, L.; Serra, A.; Puiggali, J. Study on the crystallization of multiarm stars with a poly (ethyleneimine) core and poly(E-caprolactone) arms of different length. Thermochim. Acta 2015, 607, 39-52. [CrossRef]

120. Agbolaghi, S.; Abbaspoor, S.; Abbasi, F. A comprehensive review on polymer single crystals-From fundamental concepts to applications. Prog. Polym. Sci. 2018, 81, 22-79. [CrossRef]

121. Nunez, E.; Vancso, G.J.; Gedde, U.W. Morphology, Crystallization, and Melting of Single Crystals and Thin Films of Star-branched Polyesters with Poly( $\varepsilon$-caprolactone) Arms as Revealed by Atomic Force Microscopy. J. Macromol. Sci. Part B Physics 2008, 47, 589-607. [CrossRef]

122. Armelin, E.; Almontassir, A.; Franco, L.; Puiggali, J. Crystalline Structure of Poly(decamethylene sebacate). Repercussions on Lamellar Folding Surfaces. Macromolecules 2002, 35, 3630-3635. [CrossRef]

123. Sanandaji, N.; Neway, B.; Hedenqvist, M.S.; Li, Y.; Hawker, C.J.; Takizawa, K.; Gedde, U. Crystallization and Melting Behavior of Monodisperse Oligomers of $\varepsilon$-Caprolactone. J. Macromol. Sci. Part B Physics 2012, 51, 2075-2092. [CrossRef]

124. Vasiliev, C.; Gunter, R.; Pispas, P.; Hadjichristidis, N. Crystallization pf block copolymers in restricted cylindrical geometries. Polymer 2006, 47, 330-340. [CrossRef]

125. Huang, Y.; Mai, Y.; Yang, X.; Beser, U.; Liu, J.; Zhang, F.; Yan, D.; Mullen, K.; Feng, X. Temperature-Dependent Multidimensional Self-Assembly of Polyphenylene-Based "Rod-Coil" Graft Polymers. J. Am. Chem. Soc. 2015, 137, 11602-11605. [CrossRef] [PubMed]

126. Simpson, J.H. Organic Structure Determination Using 2-D NMR Spectrocopy-A Problem-Based Approach, 2nd ed.; Ch. 2-“'Instrumental Considerations"; Elsevier: Amsterdam, The Netherlands, 2012; pp. 21-57.

127. Elschner, A.; Kirchmeyer, S.; Lovenich, W.; Merker, U.; Reuter, K. PEDOT_Principle and Applications of an Intrinsically Conductive Polymer; ch. 5- “The Synthesis of EDOT Monomer and Its Physical and Chemical Properties”; CRC Press: Boca Raton, FL, USA, 2011; pp. 47-66.

128. Zhang, S.; Zhang, W.; Zhang, G.; Bai, Y.; Chen, S.; Xu, J.; Yu, Z.; Sun, K. p-Toluenesulfonic acid catalytic polymerization of EDOT without oxidants. Mater. Lett. 2018, 222, 105-108. [CrossRef]

129. Tomsik, E.; Ivanko, I.; Svoboda, J.; Sedenkova, I.; Zhigunov, A.; Hromadkova, J.; Panek, J.; Lukesova, M.; Velychkivska, N.; Janisova, L. Method of Preparation of Soluble PEDOT: Self-Polymerization of EDOT without Oxidant at Room Temperature. Macromol. Chem. Phys. 2020, 221, 2000219. [CrossRef]

130. Elschner, A.; Kirchmeyer, S.; Lovenich, W.; Merker, U.; Reuter, K. PEDOT_Principle and Applications of an Intrinsically Conductive Polymer; ch. 6- "From EDOT to PEDOT: Oxidative Polymerization and Other Routes"; CRC Press: Boca Raton, FL, USA, 2011; pp. $67-82$.

131. Cho, W.; Wu, J.; Shim, B.S.; Kuan, W.-F.; Mastroianni, S.E.; Young, W.-S.; Kuo, C.-C.; Epps, T.H., III; Martin, D.C. Synthesis and characterization of bicontinuous cubic poly(3,4-ethylene dioxythiophene) gyroid (PEDOT GYR) gels. Phys. Chem. Chem. Phys. 2015, 17, 5115-5123. [CrossRef]

132. Qin, L.; Ding, Z.; Hanif, M.; Jiang, J.; Liu, L.; Mo, Y.; Xie, Z.; Ma, Y. Poly(3,4-dioxythiophene) soft nano-network with a compatible ion transporting channel for improved electrochromic performance. Polym. Chem. 2016, 7, 6954-6963. [CrossRef]

133. Zhao, Q.; Jamal, R.; Zhang, L.; Wang, M.; Abdiryim, T. The structure and properties of PEDOT synthesized by template-free solution method. Nanoscale Res. Lett. 2014, 9, 557. [CrossRef] 